\title{
Clinical and radiological features of extra-pulmonary sarcoidosis: a pictorial essay
}

\author{
Stefano Palmucci ${ }^{1}$ - Sebastiano Emanuele Torrisi ${ }^{2}$ - Daniele Carmelo Caltabiano ${ }^{1}$. \\ Silvia Puglisi ${ }^{2}$ - Viviana Lentini ${ }^{3}$ - Emanuele Grassedonio ${ }^{4} \cdot$ Virginia Vindigni $^{2}$.

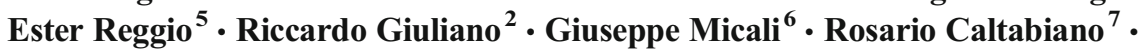 \\ Cosma Andreula ${ }^{8}$. Pietro Valerio Foti ${ }^{1}$ Giovanni Carlo Ettorre ${ }^{1} \cdot$ Simon LF Walsh ${ }^{9}$. \\ Carlo Vancheri ${ }^{2}$
}

Received: 30 December 2015 /Revised: 7 April 2016 / Accepted: 22 April 2016/Published online: 25 May 2016

(C) The Author(s) 2016. This article is published with open access at Springerlink.com

\begin{abstract}
The aim of this manuscript is to describe radiological findings of extra-pulmonary sarcoidosis. Sarcoidosis is an immune-mediated systemic disease of unknown origin, characterized by non-caseating epitheliod granulomas. Ninety percent of patients show granulomas located in the lungs or in the related lymph nodes. However, lesions can affect any organ. Typical imaging features of liver and spleen sarcoidosis include visceromegaly, with multiple nodules hypodense on CT images and hypointense on T2-weighted MRI acquisitions. Main clinical and radiological manifestations of renal sarcoidosis are nephrolithiasis, nephrocalcinosis, and acute interstitial nephritis. Brain sarcoidosis shows multiple or solitary parenchymal nodules
\end{abstract}

This article is based on electronic poster published in EPOS: F. Roccasalva, S. Palmucci, M. Piccoli, G. Cappello, R. O. A. Siverino, S. Puglisi, S. Torrisi, V. Vindigni, C. Vancheri. (2015) Imaging features of extra-thoracic sarcoidosis: a pictorial essay. EPOS ${ }^{\mathrm{TM}}$ Poster presented at ECR 2015. doi: 10.1594/ecr2015/C-2049.

Stefano Palmucci

spalmucci@sirm.org

1 Radiodiagnostic and Radiotherapy Unit, University Hospital

"Policlinico-Vittorio Emanuele", Via Santa Sofia 78,

95123 Catania, Italy

2 Regional Centre for Interstitial and Rare Lung Diseases, Department of Clinical and Molecular Biomedicine, University Hospital Policlinico-Vittorio Emanuele, Via Santa Sofia 78, 95123 Catania, Italy

3 Unit of Diagnostic and Interventional Radiology, ARNAS Garibaldi, Catania, Italy on MRI that enhance with a ring-like appearance after gadolinium. In spinal cord localization, MRI demonstrates enlargement and hyperintensity of spinal cord, with hypointense lesions on T2-weighted images. Skeletal involvement is mostly located in small bone, showing many lytic lesions; less frequently, bone lesions have a sclerotic appearance. Ocular involvement includes uveitis, conjunctivitis, optical nerve disease, chorioretinis. Erythema nodosum and lupus pernio represent the most common cutaneous manifestations encountered. Sarcoidosis in various organs can be very insidious for radiologists, showing different imaging features, often non-specific. Awareness of these imaging features helps radiologists to obtain the correct diagnosis.
4 Section of Radiological Sciences, DIBIMEF, University Hospital "Paolo Giaccone" University of Palermo, Palermo, Italy

5 Department of G. F. Ingrassia, Section of Neurosciences, University Hospital Policlinico-Vittorio Emanuele, Via Santa Sofia 78, 95123 Catania, Italy

6 Dermatology Clinic, University of Catania, Catania, Italy

7 Department of G.F. Ingrassia, Institute of Pathology, University Hospital Policlinico-Vittorio Emanuele, Catania, Italy

8 Neuroradiology and Radiology, Anthea Hospital Bari, Gruppo Villa Maria, Puglia, Italy

9 Department of Radiology, Kings College Hospital Foundation Trust, Denmark Hill, London, UK 


\section{Teaching Points}

- Systemic sarcoidosis can exhibit abdominal, neural, skeletal, ocular, and cutaneous manifestations.

- T2 signal intensity of hepatosplenic nodules may reflect the disease activity.

- Heerfordt's syndrome includes facial nerve palsy, fever, parotid swelling, and uveitis.

- In the vertebrae, osteolytic and/or diffuse sclerotic lesions can be found.

- Erythema nodosum and lupus pernio represent the most common cutaneous manifestations.

Keywords Sarcoidosis · Granulomatous disease, chronic · Multidetector computed tomography · Magnetic resonance imaging $\cdot$ Positron-emission tomography

\section{Introduction}

Sarcoidosis is a multi-systemic disorder of unknown cause, pathologically characterized by the accumulation of inflammatory cells forming non-caseating granulomas. Lesions can be located in any organ but in about $90 \%$ of patients, granulomas affect the lungs or the related lymph nodes [1].

According to Geize et al., sarcoidosis can be encountered in extra-pulmonary locations, in approximately $30 \%$ of cases [2]. Moreover, the study entitled "A Case Control Etiologic Study of Sarcoidosis" (ACCESS) provided an accurate analysis regarding distribution of the disease: in 736 sarcoidosis cases, 699 patients showed thoracic disease, and 368 out of the 736 patients had concomitant extra-thoracic disease [3-5]; isolated extra-pulmonary disease was found only in a small percentage of cases $(2 \%)[3,5]$.

The systemic location of the disease can be very insidious for radiologists: a wide variety of imaging features are found, often non-specific, which can mimic other pathological conditions $[6,7]$. Therefore, the aim of this pictorial essay is to describe the most important clinical features and the main radiological findings of sarcoidosis in various organs, in order to help radiologists in the identification of the disease.

\section{Epidemiology}

The disease affects young men and women aged between 25 and 40 years, without major differences in ethnicity. Some studies do show a greater incidence in females [8]. In about $30 \%$ of cases, there is a second peak incidence from 50 to 65 years of age. This second peak mostly affects women showing clinical characteristics that differ from those of younger patients $[9,10]$. The annual incidence varies widely from country to country. In northern Europe it is about 5-40/100,000, which represents the highest value reported; in Japan the incidence is lower, with a value of about 1-2/100,000. Afro-Americans are the most affected $(35.5 / 100,000)$, whereas white Americans have an incidence of 10.9/100,000 [8].

Normally, sarcoidosis shows a variable clinical course; it may also exhibit different extra-thoracic manifestations. These vary widely according to ethnicity: for example, involvement of the eye, liver, bone marrow, extra-thoracic lymph nodes, and skin has been more statistically associated with African Americans than with Caucasians [3, 5].

Cardiac and ocular diseases are frequently encountered in Japanese patients, erythema nodosum in northern Europeans, and ocular and granulomatous skin involvement in black patients [11-13]. In addition, regarding cutaneous lesions, Lupus pernio has been frequently observed in Puerto Ricans.

Extra-thoracic sarcoidosis involves females more frequently than males [3].

\section{Extra-pulmonary sarcoidosis: clinical and imaging features}

Extra-pulmonary sarcoidosis has been found in $30 \%$ of patients with the disease [2]. The most common site reported in the paper by Gezer et al. is the abdomen, which includes liver, spleen, biliary tree, peritoneum, and lymphatic sarcoidosis [2].

The cutaneous system and the eyes are involved with a frequency of $25 \%[14,15]$. Following data reported in the paper by Rao et al., the third most affected organ is the eye, with a frequency of involvement ranging from 10 to $60 \%$ [11]. However, according to data reported by Koyama et al., ocular sarcoidosis is found with higher frequency, being about $80 \%$ [16]. Skin lesions are found in 20 to $35 \%$ of patients with sarcoidosis [11, 17, 18]; similarly, a frequency of $25 \%$ for cutaneous involvement has been reported in other papers $[16,19]$.

The following sections below describe more in detail clinical and radiological features of systemic sarcoidosis (Table 1), focusing on abdominal, neural, musculo-skeletal, cutaneous, ocular, and cardiac manifestations.

\section{Abdominal sarcoidosis}

\section{Hepatic sarcoidosis}

Hepatic sarcoidosis occurs with a prevalence of 1-40/100,000; it generally involves young people [20]. The disease is underestimated: indeed, involvement of hepatic parenchyma is encountered - in autopsy specimens - in 50-80\% of cases [16]. In 2-60\% of patients, laboratory tests show abnormal levels, indicating an organ dysfunction [21]. Portal hypertension, cirrhosis and chronic cholestatic disease are rarely reported from patients with hepatic sarcoidosis [22]. 
Table 1 Main clinical and radiological features of sarcoidosis in different organs

\begin{tabular}{|c|c|c|}
\hline Location & Clinical features & Imaging findings \\
\hline Liver & $\begin{array}{l}\text { Hepatomegalia, enlargement of abdominal } \\
\text { lymph nodes }\end{array}$ & $\begin{array}{l}\text { Round or oval shaped hypoechoic nodules at ultrasonography; } \\
\text { Hypodense nodules on CT images; Hypointense nodules on } \\
\text { T2-weighted MRI sequences and on gadolinium-enhanced } \\
\text { T1-weighted MRI acquisitions }\end{array}$ \\
\hline Spleen & $\begin{array}{l}\text { Patients can be asymptomatic or complain } \\
\text { of fever, weight loss, and malaise }\end{array}$ & $\begin{array}{l}\text { Ultrasound reveals splenomegaly with small hypoechoic nodules; } \\
\text { Hypodense nodules after contrast-enhanced CT images; Nodular } \\
\text { lesions with low signal in all sequences and visible in the early } \\
\text { gadolinium-enhanced T1 images }\end{array}$ \\
\hline Gastro-intestinal Tract & $\begin{array}{l}\text { Disease involves gastric antrum, biliary } \\
\text { tree, and parotid glands }\end{array}$ & $\begin{array}{l}\text { Small ulcerations of gastrointestinal tract; Enlargement of parotid } \\
\text { glands can be observed, with inhomogeneous or nodular pattern on } \\
\text { enhanced CT images; Increased T2-signal intensity on MRI } \\
\text { acquisitions of parotid glands }\end{array}$ \\
\hline Lymphatic System & $\begin{array}{l}\text { Lymphadenopathy or increased number of } \\
\text { normal sized nodes }\end{array}$ & $\begin{array}{l}\text { Enlarged nodes can be located in the periportal or para-aortocaval } \\
\text { region, close to the liver hilus, adjacent to the celiac trunk or } \\
\text { pancreas }\end{array}$ \\
\hline Peritoneum & Ascites and multiple nodules & $\begin{array}{l}\text { Hypoattenuating nodules on CT images, fluid accumulation in the } \\
\text { abdomen }\end{array}$ \\
\hline Kidneys & $\begin{array}{l}\text { Nephrolithiasis, nephrocalcinosis, } \\
\text { nephrogenic diabetes insipidus, renal } \\
\text { insufficiency, acute interstitial nephritis }\end{array}$ & $\begin{array}{l}\text { "Striated nephrogram" can be found on CT and MRI acquisitions; } \\
\text { Granulomatous pseudotumor appears as hypo-/iso-/ } \\
\text { hyperatteanuating area on unenhanced CT scans, hypodense after } \\
\text { contrast administration; Granulomatous pseudotumor shows low } \\
\text { signal on early and delayed images after gadolinium administration }\end{array}$ \\
\hline Central Nervous System & $\begin{array}{l}\text { Signs of cranial nerve involvement; } \\
\text { headache, seizure, meningeal irritation }\end{array}$ & $\begin{array}{l}\text { Lesions are hyperintense on T2-weighted MRI images, located in the } \\
\text { white and grey matter; Leptomeningeal localizations are more } \\
\text { visible after contrast injection, showing increased signal on } \\
\text { enhanced T1 acquisitions }\end{array}$ \\
\hline Bone & $\begin{array}{l}\text { Hands and feet are the most common } \\
\text { locations }\end{array}$ & $\begin{array}{l}\text { On conventional radiography, lesions produce a lacy pattern of } \\
\text { osteolytic areas in the digits; Large bone and axial skeleton lesions } \\
\text { can be detected as radiolucent or sclerotic areas }\end{array}$ \\
\hline Heart & $\begin{array}{l}\text { Conduction disturbances and arrhythmias, } \\
\text { pericarditis }\end{array}$ & $\begin{array}{l}\text { Granulomatous lesions are observed as areas of focal enhancement on } \\
\text { cardiac MRI, most frequently located in myocardial wall or } \\
\text { subepicardial region }\end{array}$ \\
\hline Skeletal Sarcoidosis & $\begin{array}{l}\text { Involves hand and feet; large bones and } \\
\text { axial skeleton involvement is uncommon }\end{array}$ & $\begin{array}{l}\text { Sclerotic areas consisting of hyperdense homogeneous areas, round or } \\
\text { oval in shape; osteolysis produces a hypodense appearance } \\
\text { Lesions with high signal intensity on T2-weighted images, high- } \\
\text { density proton sequences and STIR acquisitions; on T1-weighted } \\
\text { images, lesions are generally hypointense }\end{array}$ \\
\hline
\end{tabular}

Commonly, imaging demonstrates hepatomegaly, with homogeneous appearance of parenchyma [16]; very often, this radiological feature is associated with splenomegaly and enlargement of abdominal lymph nodes [20], which are encountered close to the liver hilus or in celiacal region. However, in $5-15 \%$ of cases, multiple nodular granulomas, ranging from 1 to $2 \mathrm{~mm}$ to several centimeters in diameter, become visible on CT and MRI [16]. Nodular involvement-according to Karagiannidis et al. - can be detected in low percentage $(<5 \%$ of cases) [20].

Granulomatous lesions are located in the portal and periportal spaces of hepatic sinuses and generally exhibit "an identical stage of maturation" $[20,23]$. They may be seen as round or oval shaped hypoechoic nodules at ultrasound (Fig. 1), involving hepatic parenchyma in a diffuse or limited form. These nodules are hypodense on CT images and show a low signal on MRI scan, especially in T2-weighted fat-saturated acquisitions. The nodules are generally hypointense on gadolinium-enhanced T1-weighted acquisitions [23-25]. However, signal intensity depicted on T2-weighted images reflects the degree of activity of disease: nodules can appear hyperintense in case of inflammation, due to oedema and high vascular permeability (Fig. 2) [26]. Similarly, on diffusion weighted imaging (DWI) acquisition, nodules with inflammation appear as high signal intensity lesions, with restriction on apparent diffusion coefficient (ADC) map. Fibrotic nodules show low signal on T2-weighted and diffusion sequences [26].

\section{Splenic sarcoidosis}

Splenic sarcoidosis is generally associated with lung disease; however, normal chest radiography is observed in one quarter 
Fig. 1 A 61-year-old female patient affected by pulmonary sarcoidosis, proved by biopsy. Routine abdominal ultrasound exam (on Fig. 1a and b) shows multiple, small, randomly distributed, hypoechoic nodules in the liver parenchyma. Nodules were histologically related to sarcoidosis

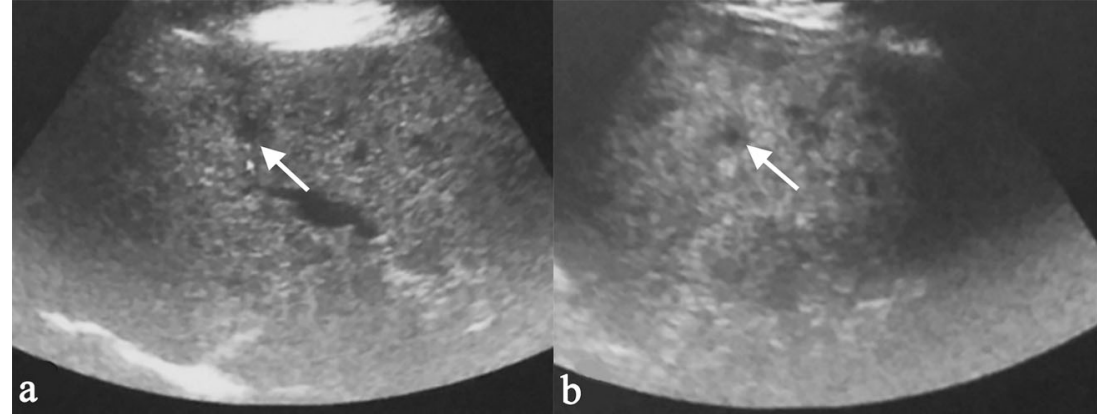

to one third of patients with splenic sarcoidosis [27]. Splenic involvement has been reported in a variable percentage, ranging from 24 to $59 \%$ of biopsies [28-30]; at autopsy, the frequency of sarcoid lesions in the splenic parenchyma is about $41 \%$ [31].

Patients can be asymptomatic, or complain of fever, weight loss, and malaise [21, 32]. In the series reported by Warshauer et al., splenomegaly has been found in one third of cases [32]. Hepatic and splenic contemporary involvement has been reported in 5-15\% of cases [32].

Splenic sarcoidosis can be present in a homogeneous fashion or in a nodular pattern [2, 27, 33]. At ultrasound, splenic lesions may be detected as small nodules, with hypoechoic attenuation in comparison to surrounding parenchyma. On CT images, lesions are generally revealed as small hypodense nodules after contrast administration (Fig. 3); nodules can be larger than $1 \mathrm{~cm}$ in size, with a tendency to confluence (Fig. 4).
On MRI acquisitions, nodular lesions show low signal in all sequences [34]; the visualization reaches an optimal level on T2-weighted acquisition with fat suppression and in the early gadolinium-enhanced T1 images (Fig. 5) [34, 35]. It has recently pointed out that MRI is able to monitor the activity of the disease. On T2-weighted images, nodules can appear hyperintense in cases of inflammation due to oedema and high vascular permeability; also, on DWI acquisitions, inflammation of nodules show high signal intensity, with restriction on ADC map [26].

Parenchymal lesions show increased FDG uptake on PETCT [36]: low-density areas on CT reveals multiple foci of increased metabolic activity on PET images (Fig. 6).

\section{Gastrointestinal sarcoidosis}

Among abdominal sarcoidosis, autopsy revealed only a small percentage of cases $(5 \%)$ located in pancreatic tissue,
Fig. 2 Hepatosplenic sarcoidosis. Liver MRI demonstrates multiple, scattered, small, hyperintense nodules (white arrows) on T2-weighted images (Fig. 2a and b) and on diffusion weighted imaging (DWI) (Fig. 2c and d); after gadolinium administration, nodules appear hypointense (Fig. 2e and f). In hepato-splenic sarcoidosis, T2 signal intensity reflects the degree of activity of disease: nodules can appear hyperintense in case of inflammation due to oedema and high vascular permeability; they have hypointense signal, when fibrosis is prevalent (see curved arrows for nodular lesions of the spleen)

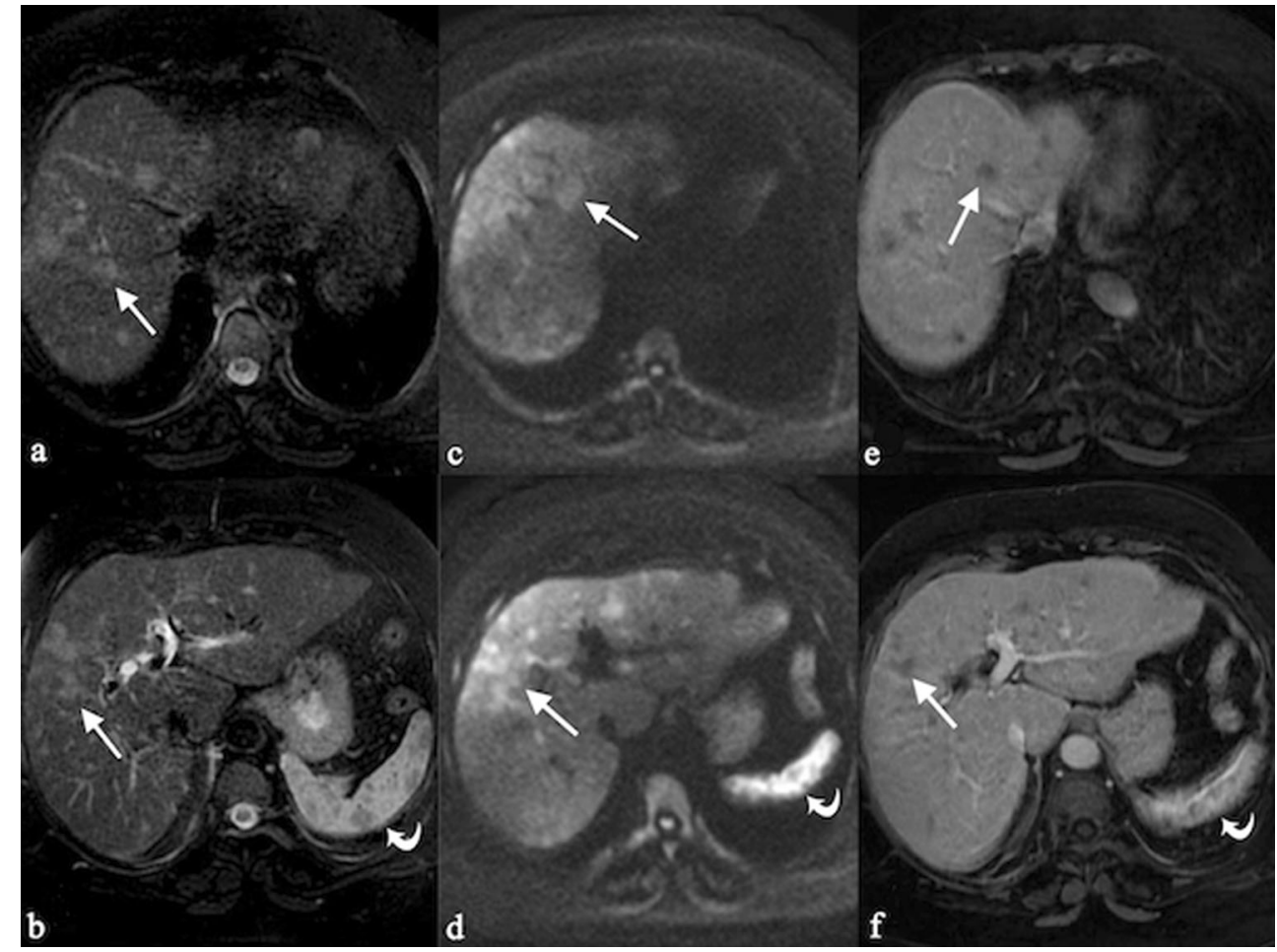




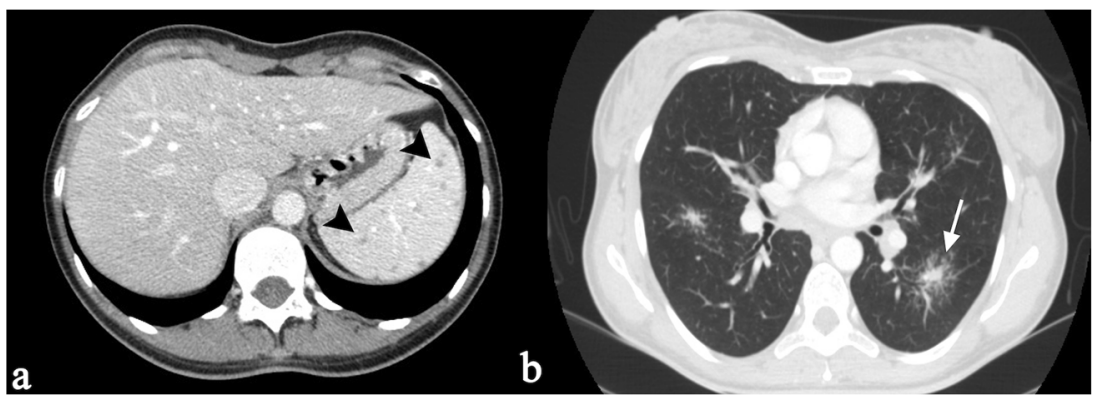

Fig. 3 A 40-year-old female patient affected by pulmonary and splenic sarcoidosis. Figure 3a shows splenic sarcoidosis in a nodular pattern; the nodules (black arrowheads) are revealed as small hypodense nodules on

intestinal tract, and testes [21]. The gastric antrum is the area most frequently involved [11]. Along the gastrointestinal tract, small ulcerations and mucosal thickening can be observed.

The biliary tree may be involved in extra-hepatic or intrahepatic pattern. Granulomatous lesions develop in the portal triad, causing a cholestatic pattern.

Extra-hepatic involvement of the biliary tree can be caused by multiple small granuloma of the wall; the radiological appearance in these cases may simulate a cholangiocarcinoma; in many cases, the biliary tree may be compressed by enlarged abdominal nodes.

According to Koyama et al., in $6 \%$ of cases parotid glands may have sarcoidosis involvement; generally, the disease is found bilaterally, with enlargement of glands [16]. An inhomogeneous pattern can be observed on enhanced CT images (Fig. 7); increased T2-signal intensity and nodular lesions are observed on MRI acquisitions (Fig. 8). Increased uptake of Gallium-67 reproduces the typical "Panda" sign, even if this radionuclide accumulation is also described in other pathological entities (lymphoma and HIV infection) [36].

\section{Lymphatic and peritoneal sarcoidosis}

Lymphatic abnormalities have been already described as abdominal manifestations of sarcoidosis, consisting of "lymphadenopathy or increased number of normal sized nodes" [37]; lymph nodes are generally $1-2 \mathrm{~cm}$ in size. In a previous experience, abdominal adenopathy was reported in approximately $30 \%$ of patients; in these case series, adenopathy was defined as "two or more nodes with a short axis diameter greater than $6 \mathrm{~mm}$ " [21]. contrast-enhanced CT images. Ill-defined pulmonary opacities, with small nodules around, are also depicted on Fig. 3b, resembling the typical sarcoid galaxy sign (white arrow)

Enlarged nodes can be observed in different locations: in the periportal region, close to the liver hilus (Fig. 9), or between portal vein and vena cava. They can be found adjacent to the celiac trunk or pancreas (Fig. 10), or in a paraaortic disposition. Lymph nodes are also found around iliac vessels, or in the mesentery. A diffuse abdominal nodes involvement can be observed (Fig. 11). Necrosis or calcifications are rare in sarcoidosis [21].

Lymphatic involvement is frequently associated with pulmonary disease, and this can be very helpful for radiologists in order to achieve a correct diagnosis. When the disease is limited to the lymphatic system in mediastinum and in the abdomen, a differential diagnosis from other disorders, e.g. lymphoma, may be very difficult.

Peritoneal sarcoidosis is extremely rare [2, 38-41]. It can appear with ascites and multiple nodules: these imaging features - as reported by Gezer et al.- - should be differentiated from other pathological conditions, which include carcinomatosis, tuberculosis, and fungal infections [2].

\section{Renal sarcoidosis}

In sarcoidosis, the real incidence and prevalence of renal involvement is difficult to establish, because the disease can occur in a variable manner; in most cases, it has been found in 35 to $50 \%$ of patients [42]. Main clinical manifestations are nephrolithiasis, nephrocalcinosis, nephrogenic diabetes insipidus, renal insufficiency, and acute interstitial nephritis with or without granuloma; however, many patients with renal involvement are asymptomatic.
Fig. 4 Splenic sarcoidosis in a 58-year-old female. Splenic parenchyma, on Fig. 4a, appears slightly inhomogeneous. After contrast administration (Fig. 4b and c), large nodules (exceeding $1 \mathrm{~cm}$ ) with hypodense appearance are clearly depicted

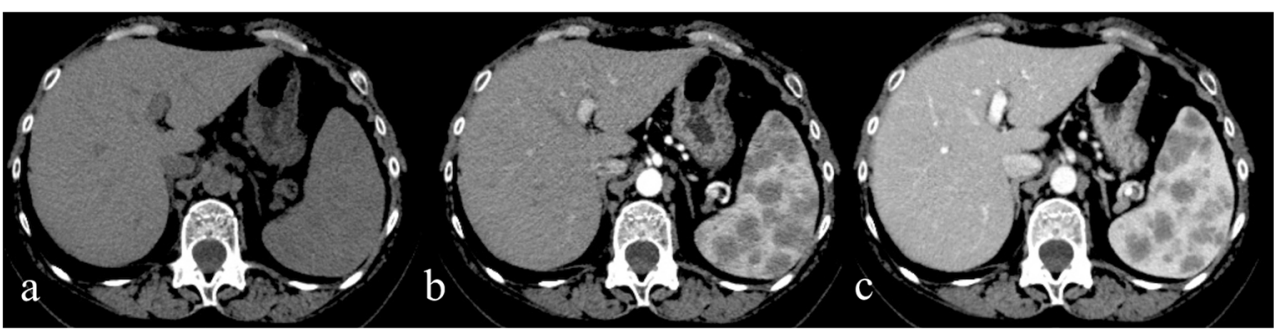


Fig. 5 MRI appearance of a splenic sarcoidosis (same patient as Fig. 2). The visualization of the nodules reaches an optimal level on $\mathrm{T} 2$-weighted acquisition with fat suppression (Fig. 5a) and in the early gadolinium-enhanced T1 images (Fig. 5b)

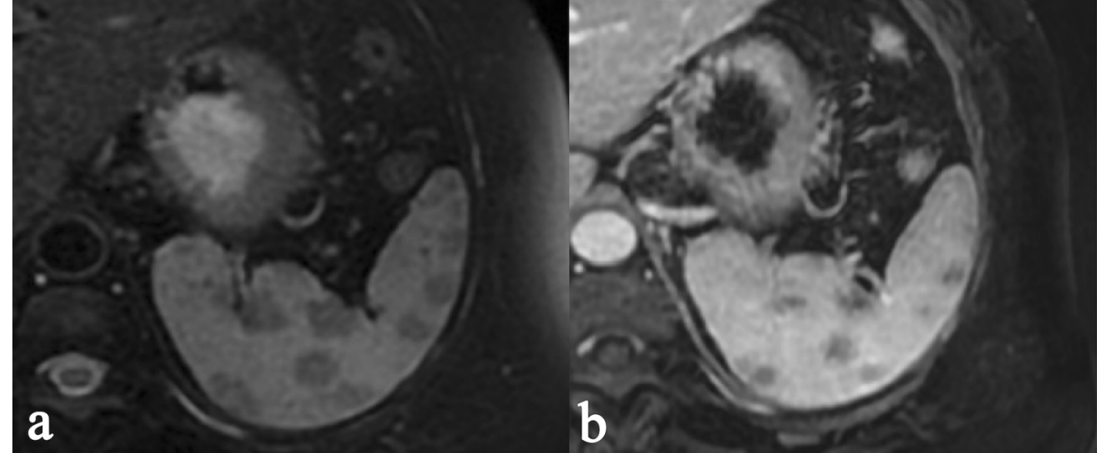

The increased levels of 1,25-dihydroxyvitamin, produced by mononuclear cells trapped in pulmonary alveoli, determines a greater absorption of calcium: this leads to hypercalcemia and consequential nephrolithiasis and nephrocalcinosis [43].

The prevalence of interstitial nephritis in sarcoidosis oscillates from 7 to $27 \%[44,45]$. The renal involvement may be with or without granuloma. Granuloma interstitial nephritis is the typical histological finding and is defined "naked with no cuff of inflammatory cells with presence of asteroid bodies and calcification" [46]. This lesion differs form tuberculosis granuloma for the absence of necrosis.
Enhanced CT images may show signs of interstitial nephritis $[21,47,48]$ with the typical "striated nephrogram" represented by ill-defined hypodense lines into the renal parenchyma. Diffusion MRI sequences show interstitial nephritis as hyperintense areas, with signal restriction on apparent diffusion coefficient map.

Rarely, radiological features of renal sarcoidosis can be represented by granulomatous pseudotumour; these lesions are generally incidentally discovered during CT examination. They can appear as hypo-, iso-, or hypeattanuating areas on unenhanced CT scans; after contrast administration, they are hypodense to the surrounding renal parenchyma (Fig. 12)
Fig. 6 FDG uptake on PET-CT in a 57-year-old woman affected by pulmonary and splenic sarcoidosis. Increased metabolic activity is appreciable in the left pulmonary hilum, due to pathological lymph nodes (white arrowheads on Fig. 6a-b). Similarly, splenic foci of increased metabolic activity are clearly seen on axial CT-PET acquisitions (empty white arrowheads respectively on Fig. $6 \mathrm{c}-\mathrm{d}$ ), and on coronal and sagittal reformatted images (white arrows in Fig. 6e-h)
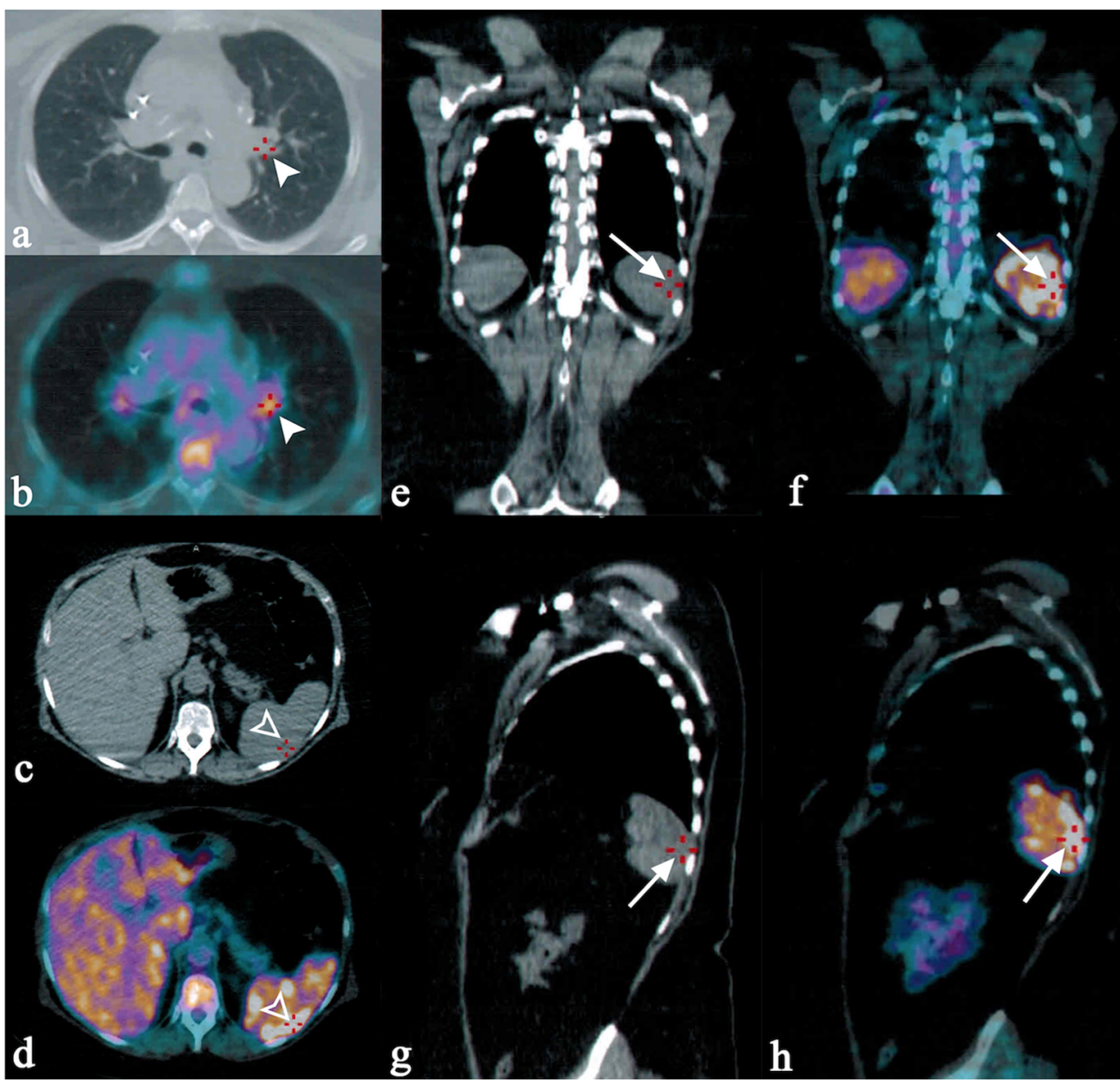

g

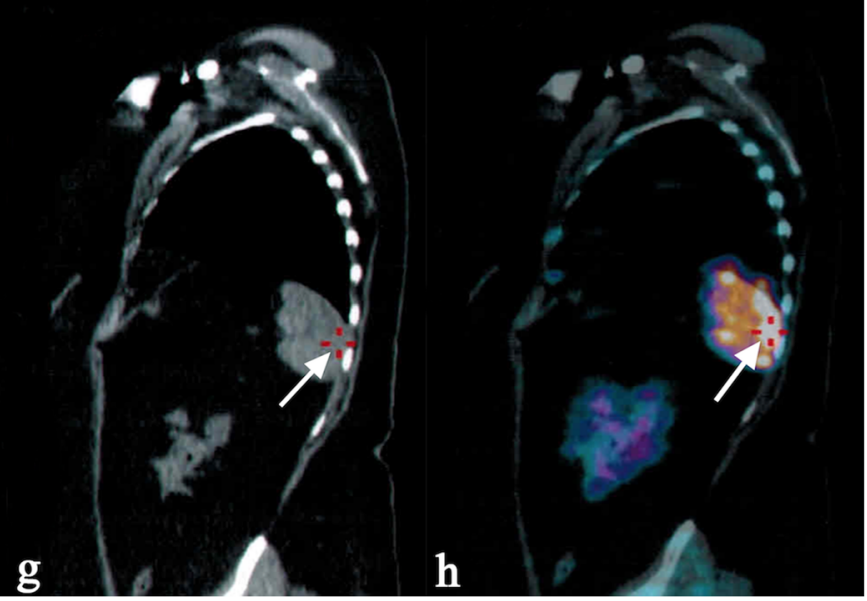


Fig. 7 Parotid gland sarcoidosis (histologically proven). On enhanced-CT images, parotid glands show inhomogeneous pattern (white arrowheads), with multiple and punctuate small hypodense lesions. Figure 7c show typical pattern of thoracic disease on $\mathrm{CT}$ acquisitions

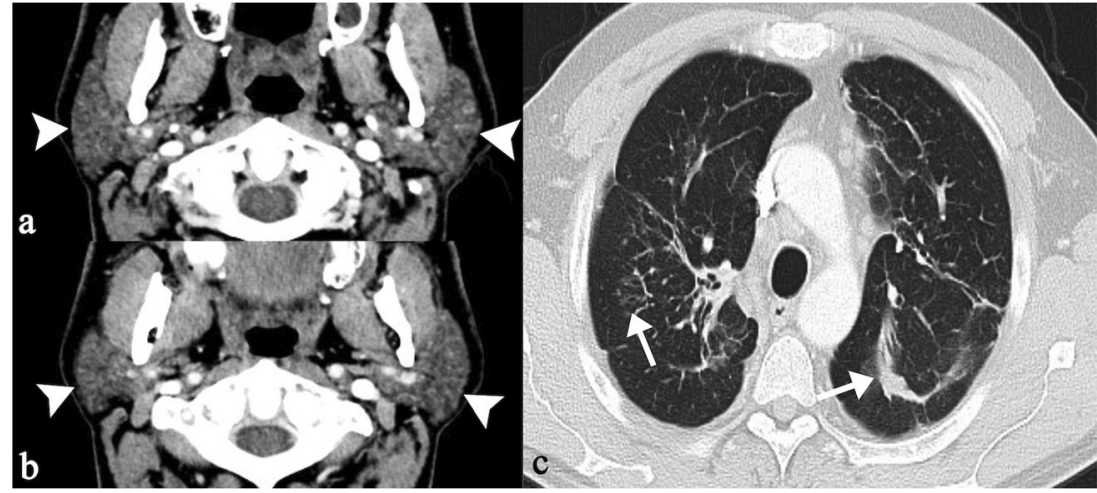

[48]. Differential diagnosis includes lymphoma or other tumours. On MRI acquisition, lesions show heterogeneous signal on unenhanced sequences and appear hypointense on early and delayed images acquired after gadolinium administration [48].

The urinary manifestations of sarcoid nephritis are nonspecific: the alterations of the urine analysis are similar to those of chronic tubular pathologies. Biopsy is the only way to make a diagnosis, showing normal glomeruli with interstitial infiltration of mononuclear cells and non-caseating granulomas; occasionally, it may be also depicted with glomerular disease $[49,50]$.

\section{Neurosarcoidosis}

Central nervous system (CNS) involvement is reported in $25 \%$ of cases at autopsy; in a post-mortem series, neural sarcoidosis was detected with a frequency of 14-27\% [51-54]. Symptoms due to neurosarcoidosis are not frequently observed, being encountered in less than $10 \%$ of patients [16].

The disease shows a special predilection for the basal cisterna of the brain; cranial nerve involvement is frequent, influencing the clinical manifestation of disease. Facial nerve palsy, for example, is a typical manifestation of brain sarcoidosis in young adults [16]. It may be associated with chronic fever, swelling of parotid gland and uveitis, configuring the typical "Heerfordt's syndrome" (Fig. 13).

Other symptoms associated with neural sarcoidosis are headache, seizure, and signs of meningeal irritation [55, 56]. Involvement of optical nerve leads to loss of vision, with a poor prognosis [57].

Diagnosis of sarcoidosis can be performed following the criteria reported in the study by Pawate et al., in which the presence of neurosarcoidosis is evaluated as definite, probable, and possible. According to their criteria [57], the disease is graded as "definite" when detected on histological specimens. It is labelled as "probable" when: a) laboratory tests are positive for CNS inflammation (elevated levels of cerebrospinal fluid protein or MRI features compatible with neurosarcoidosis) b) detection of systemic sarcoidosis (positive histology and/or least two indirect indicators from gallium scan, chest imaging and serum angiotensin-converting enzyme); the disease is considered possible when previous criteria are not satisfied [57].

Lesions appear hyperintense on T2-weighted MRI images, located in the superficial and deep white matter; sometimes, these imaging features may resemble lesions of multiple sclerosis [58]. Also grey matter lesions are generally hyperintense on T2-weighted sequences. In the series reported by Pawate et al., contrast-enhancing parenchymal white matter lesions were found in 10 out of 54 cases (19\%) [57].
Fig. 8 Parotid sarcoidosis (histologically proven), with enlargement of glands (white arrows). Nodular lesion is clearly depicted in the parenchyma of left parotid (white arrowheads in Fig. 8a and b)

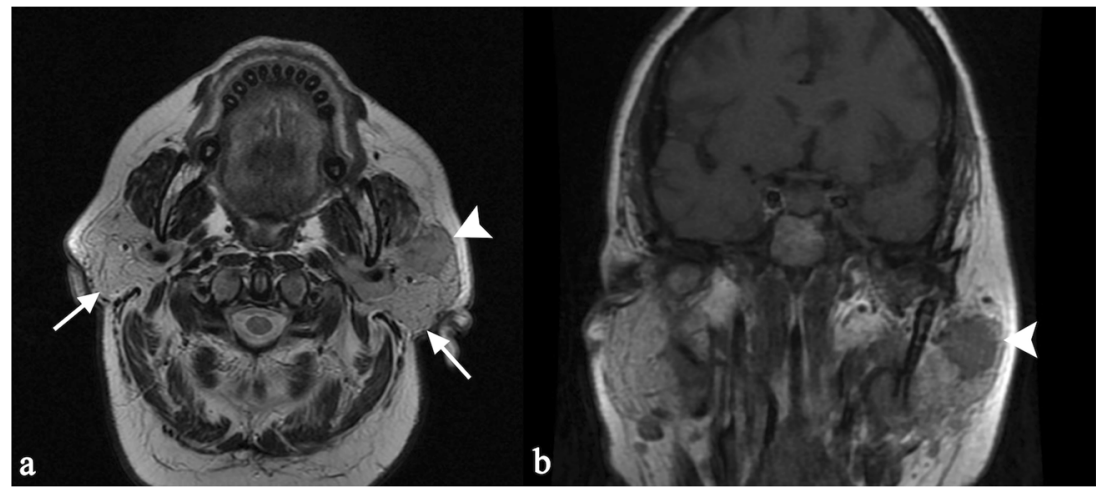


Fig. 9 A 66-year-old female patient affected by sarcoidosis, which involves mediastinal and abdominal lymph nodes (histologically proven).

Unenhanced abdominal CT image (Fig. 9a) demonstrate enlarged lymph nodes (white arrows), located in perihepatic region and close to the liver hilus; inside these lymph nodes, very small calcifications are recognizable (black arrowheads). Chest CT-scan shows mediastinal lymphadenopathy, with some punctate calcifications (white arrowhead on Fig. 9b). After contrast administration, both CT and MRI acquisitions show inhomogeneous enhancement of enlarged lymph nodes (white arrowheads on Fig. 9c and d)

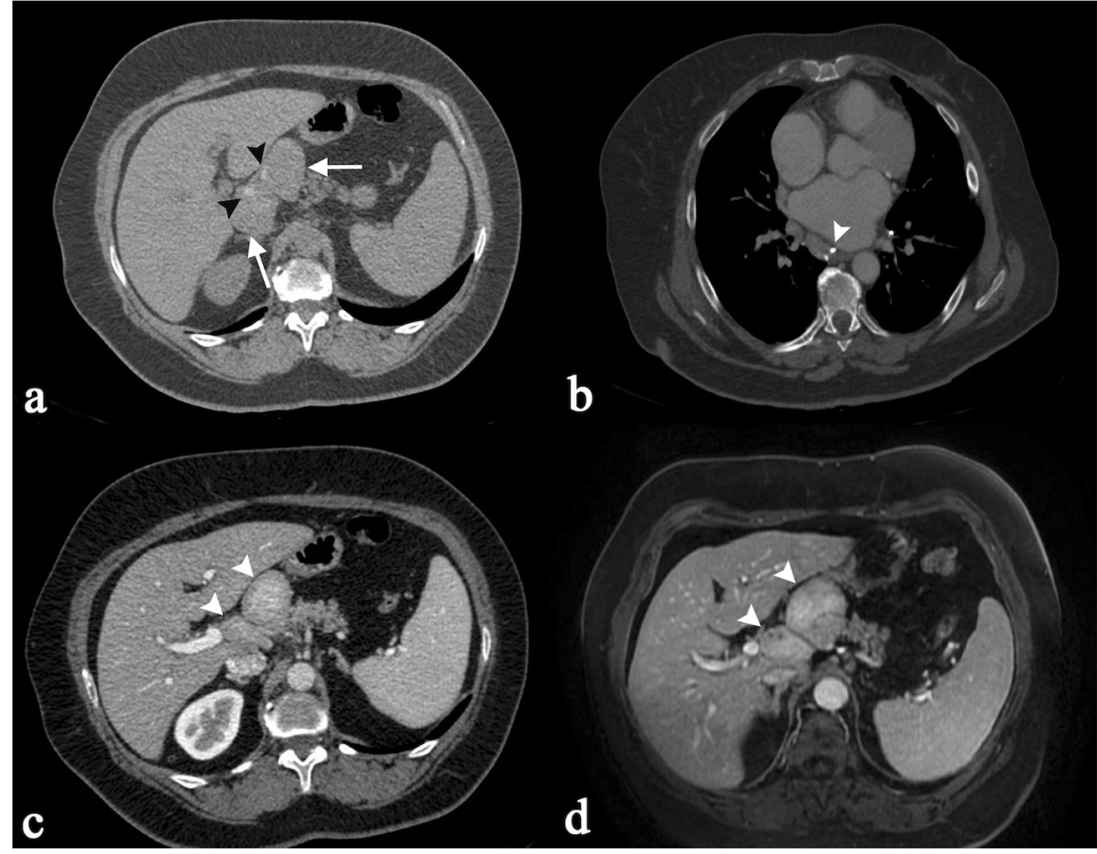

Dural thickening is generally isointense to the grey matter on T1-weighted acquisitions, hypointense on T2-weighted sequences, with contrast enhancement after gadolinium injection [59].

Leptomeningeal localizations are more visible after contrast injection, showing increased enhancement (Fig. 14) [58]. As reported by Urih et al., and subsequently by Christoforidis et al. [59], leptomeningeal infiltration involves frequently the suprasellar and frontal basal meninges.

Nodules can be solitary or multiple, showing enhancement after contrast injection with a ring-like appearance in the activity phase: this appearance can simulate glioblastoma or metastases. An intracranial mass presentation has been also reported in the literature, simulating a brain neoplasm [57].

Spinal sarcoidosis is reported in about 4-28 \% of cases; it occurs predominantly in old people and has a poor prognosis [60]. The disease may be intramedullary or extramedullary.
Junger et al. distinguish four stages of disease: 1) leptomeningeal enhancement; 2) fusiform spinal cord enlargement; 3 ) focal or diffuse intramedullary disease; 4) spinal cord atrophy [61].

MRI features of stage 1 and 2 disease include leptomeningeal thickening, with hyperintense signal on enhanced T1-weigheted images [60]. In cervical and thoracic regions, intramedullary lesions appear hypointense in T2weighted MRI sequences with hyperintensity of the associated oedema; they show enhancement (Fig. 15) on T1-weighted images after contrast injection [58].

\section{Skeletal sarcoidosis}

The skeletal system represents a rare localization of sarcoidosis [62]. Radiological features of skeletal locations have been described for the first time in 1910 by Rieder [62, 63]. It occurs in a variable range of percentages, from $9 \%$ up to
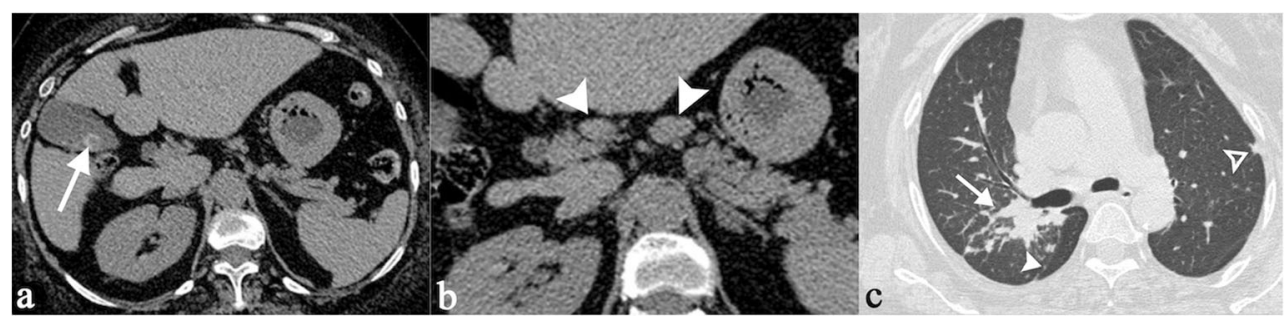

Fig. 10 Incidental sarcoidosis diagnosis in a 59-year-old woman complaining of acute abdominal pain. Unenhanced CT scan shows a gallbladder calculus (white arrow on Fig. 10a) and some peri-pancreatic lymph nodes (white arrowheads on Fig. 10b); then CT scan extended

through the chest (Fig. 10c) showed multiple, small subpleurical nodules. Histological exam confirmed diagnosis of sarcoidosis for the mentioned peri-pancreatic lymph nodes 
Fig. 11 CT scan of a 55-year-old woman with multiple

histologically proven sarcoidosis lymphadenopathy. Contrastenhanced axial CT images

(Fig. 11a-c) show multiple enlarged and confluent lymph nodes, located in the mediastinum (Fig. 11a), in the celiac region (Fig. 11b), and in the mesentery (Fig. 11c). Coronal MPR image (Fig. 11d) clearly depicts lymphadenopathy in the right side of the mediastinum, in the aortopulmonary recess (white arrow), at the right paratracheal level (empty white arrowheads), and in the left perirenal space (white asterisk). Spleen enlargement can also be detected (white curved arrow)

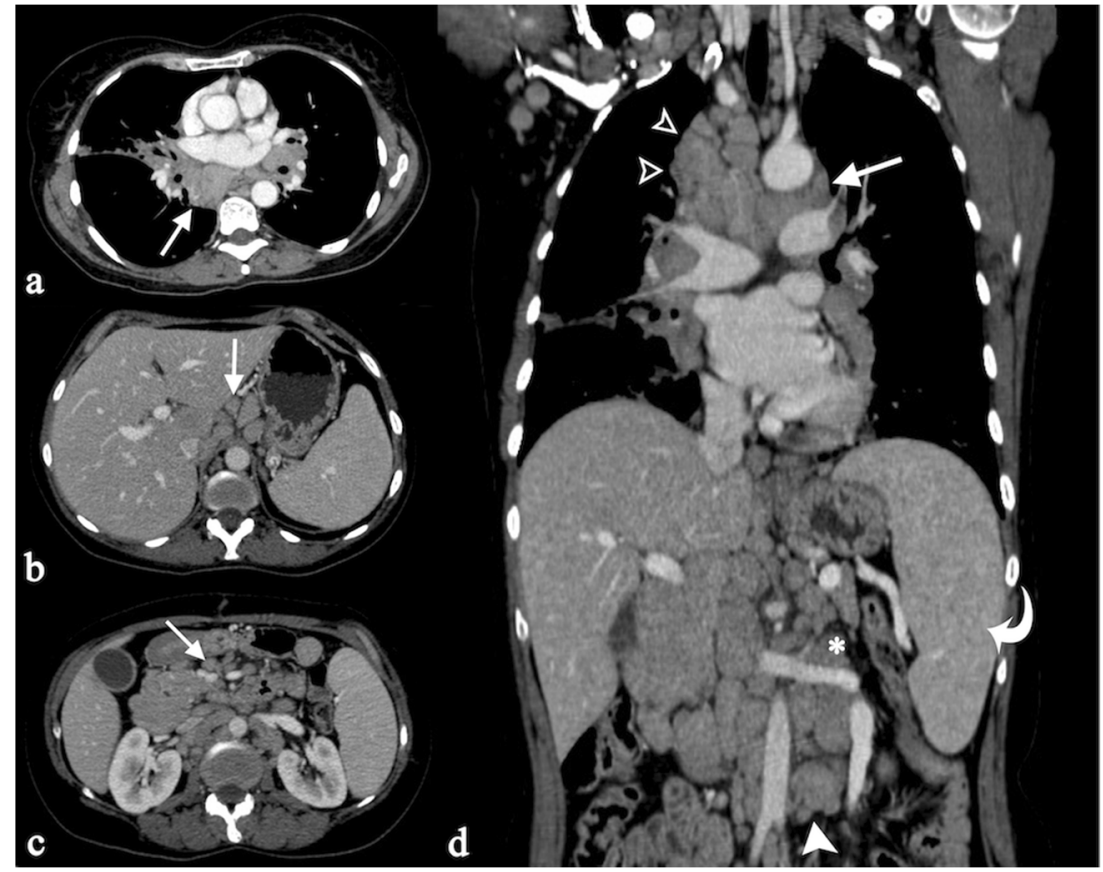

$39 \%$ [64]. However, its frequency can be underestimated, because bone lesions are often asymptomatic [6]; frequently, the disease is misdiagnosed, being interpreted as metastatic lesions [65].

The disease generally involves hands and feet, which have been reported in several reviews as the most affected locations $[62,64]$. On conventional radiography, lesions produce a lacy pattern of osteolytic areas in the digits (Fig. 16) [19, 66-68]; cortical erosions and pathological fractures may be observed [19].
Large bones and axial skeleton involvement is uncommon; however, the disease may be encountered in ribs, long bones, skull and vertebrae. Axial skeleton disease, without pulmonary lesions, is rarely reported [6].

Lesions of large bone and axial skeleton can be detected as radiolucent (Fig. 17) or sclerotic areas (Fig. 18) [66]. Sclerotic areas are well depicted on CT images, consisting of hyperdense homogeneous areas, round or oval in shape (Fig. 18); osteolysis produces a hypodense appearance, and differential diagnosis from metastatic lesions is required.
Fig. 12 Multiorgan sarcoidosis, with multiple hypodense lesions in the renal parenchyma (white arrows in Fig. $12 \mathrm{a}-\mathrm{c}$ ). In the left kidney, in the lower part of the parenchyma, lesions have nodular appearance. Splenomegaly can also be observed (white arrowheads). In the Fig. 12d, a sarcoidosis pattern is observed on HRCT images (white arrows). Sarcoid lesions in the renal parenchyma were confirmed by biopsy

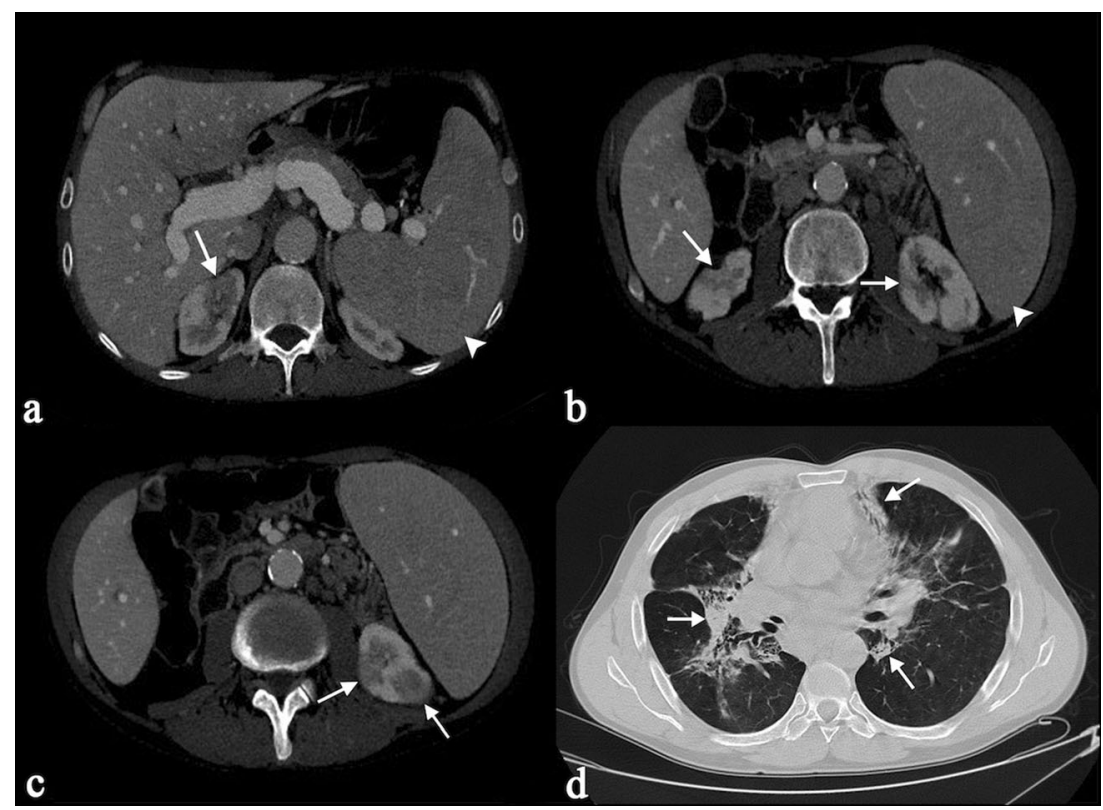




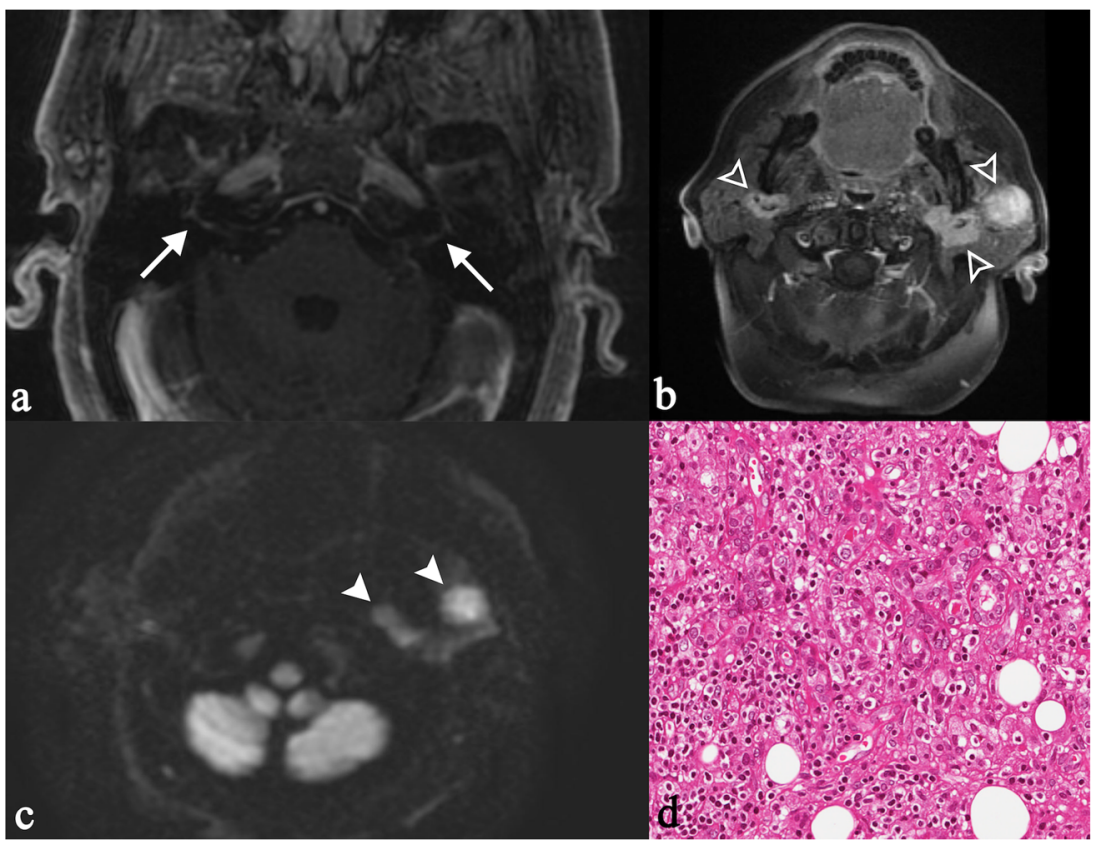

Fig. 13 "Heerfordt's syndrome" in a 60-year-old woman. Clinically, the patient complained of sudden appearance of blurred vision, headache, and mouth deviation to the left after fever. MRI shows bilateral enhancement of facial nerve (white arrows on Fig. 13a), recognizable on T1weighted image obtained after gadolinium administration. She showed a complete facial palsy and a bilateral enlargement of the cheeks. Physical examination revealed an unpainful enlargement of the left parotid gland, left facial nerve and left abducent nerve palsy. Nodular lesions were found in the parotid glands (same patient in Fig. 8), with evident contrast enhancement on T1-weighted acquisitions after contrast enhancement (Fig. 13b, empty white arrowhead) and on DWI sequences (Fig. 13c, white arrowheads). Chest CT scan and fibrobronchoscopy with bronchoalveolar lavage were suggestive of sarcoidosis. The biopsy of the left parotid gland depicted dense, non-caseating granulomatous infiltrate (Fig. 13d). Lymphocytes and epithelioid histiocytes with abundant eosinophilic cytoplasm and oval vesicular nuclei are observed (H\&E 250X). The clinical, radiological and histopathological patterns were consistent with the diagnosis of Heerfordt's syndrome
Fig. 14 Leptomeningeal localizations of sarcoidosis. Lesions are more visible on enhanced T1-weighted acquisitions, with increased enhancement along the surface of the brainstem (white arrows in Fig. 14a-b). Sarcoid nodules are also visible in the superior cerebellar cistern (white arrows in Fig. 14c-d)

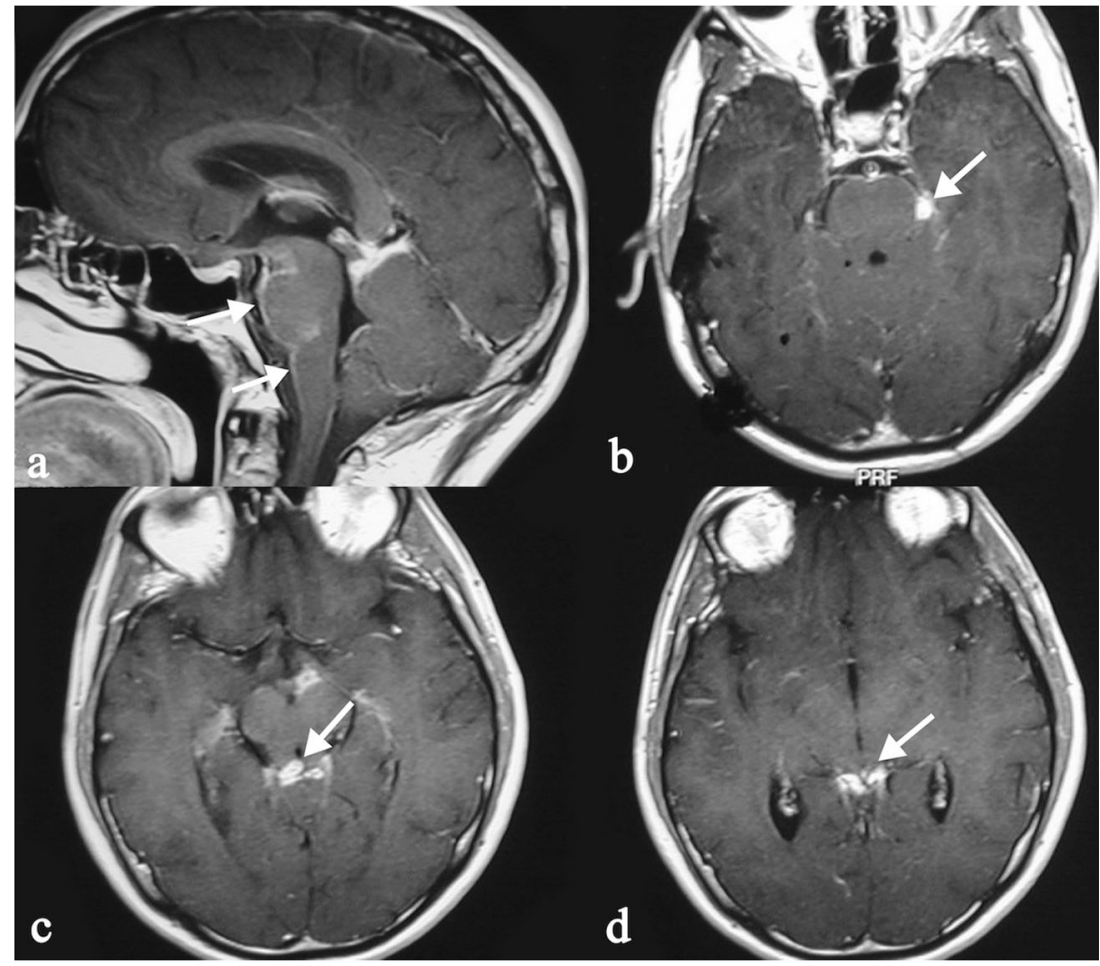


Fig. 15 MRI images show spinal cord involvement in a 54-year-old man. T2-weighted image

(Fig. 15a) demonstrates an extensive area of high signal intensity in the spinal cord (white arrow). On enhanced T1weighted acquisitions, a peripheral enhancement (white arrows) can be depicted (Fig. 15b and c), suggesting meningeal involvement

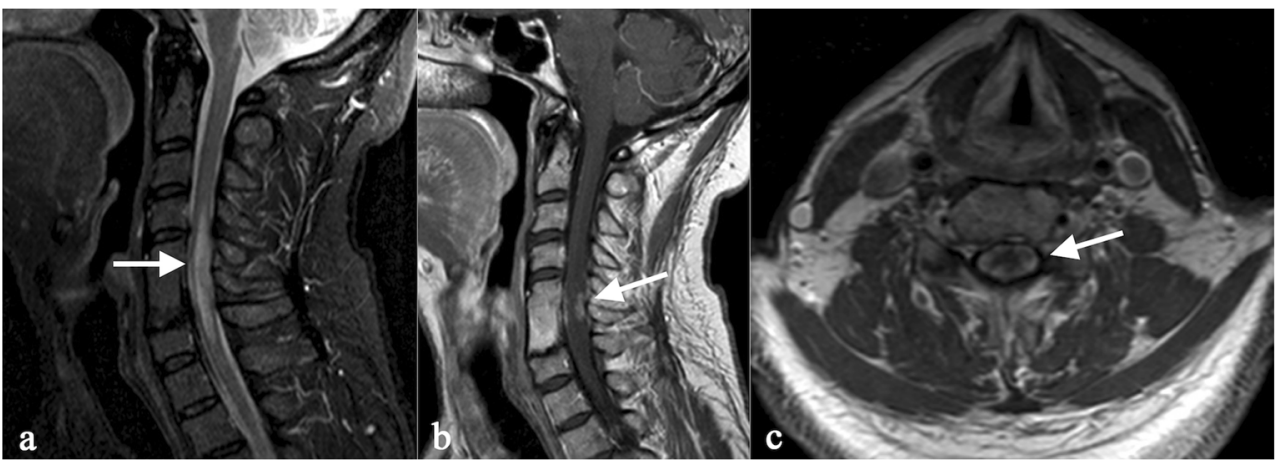

The MRI appearance of bone lesions is heterogeneous. Vardahanabuhuti et al. described how lesions can appear as bone marrow infiltration areas, "round, cannonball-like or intramedullary lesions"; lesions can reproduce a "starry sky appearance" [19]. Sarcoid lesions show high signal intensity on T2-weighted images, high-density proton sequences and STIR acquisitions; on T1-weighted images, lesions are generally hypointense.

In patients with sarcoidosis, skeletal FDG uptake can be observed (Fig. 19); these increased sites of metabolic activity are not specific. In combination with thoracic features of sarcoidosis, bone sites of increased uptake can be interpreted as "skeletal sarcoidosis" [36]. Muscle involvement is frequently misdiagnosed, being reported as chronic myopathy, acute myositis, or pseudotumour [69].

\section{Ocular sarcoidosis}

Ocular involvement occurs in approximately $25-60 \%$ of patients with systematic sarcoidosis, more frequently in the third decade (first peak of incidence) and between the sixth and the seventh decade (second peak of incidence) [70]. This may represent the initial manifestation of the disease [71], or may co-exist with asymptomatic systemic disease and can be vision-threatening.

In most cases (about $20 \%$ ), uveitis is the first common manifestation: symptoms that patients complain of include tearing, photophobia, pain, infection, lacrimation, redness. However, these symptoms can be absent: "silent uveitis" is very insidious because it may produce permanent ocular damage before treatment. The common type of uveitis is often anterior in black patients, posterior in white patients, specifically in elderly female patients [72-74]. Blindness in at least one eye occurs in about $10 \%$ of patients and the main cause is cystoid macular oedema $[75,76]$.

In the anterior segment, conjunctivitis occurs in 7 $70 \%$ of the patients with ocular sarcoidosis and, together with lacrimal gland involvement, is usually asymptomatic. The sarcoidosis granulomas in the eyes have the appearance of yellow "millet-seed" nodules. When the disease involves the posterior part of the eyes, it is frequently associated with neurological manifestations: optic nerve disease, cranial nerve palsies, encephalopathy, and disorders of the hypothalamus and pituitary gland [77, 78].
Fig. 1653 year-old man with hand involvement. A lacy pattern with small osteolytic areas is recognizable in the digits (white arrows in Fig. 16a and b)

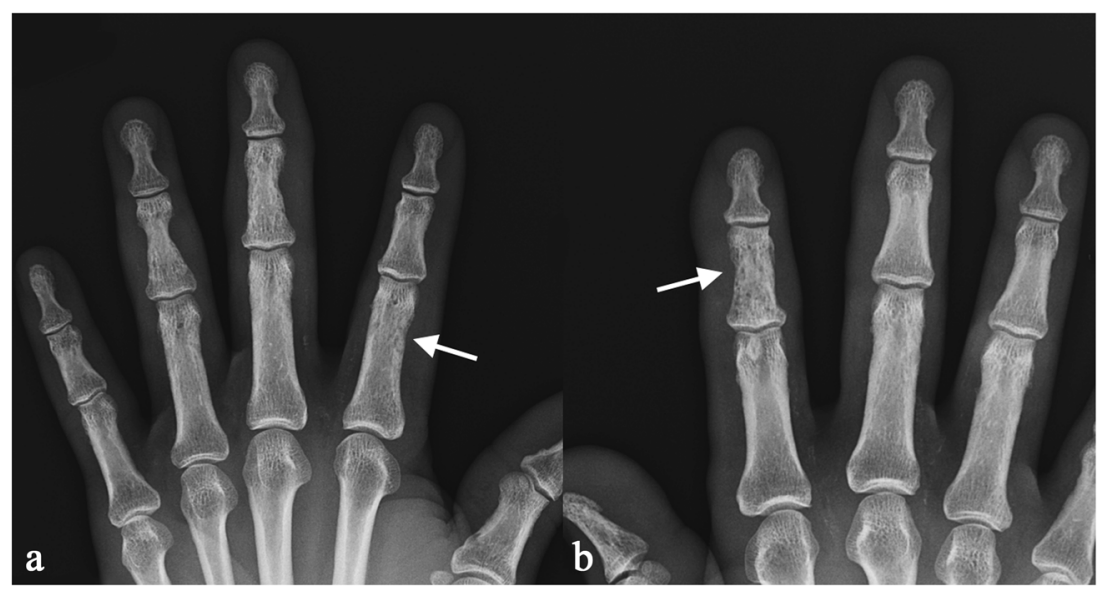


Fig. 17 Multiple bone lesions in a 51 year-old man. Sagittal multiplanar CT image (Fig. 17a) and axial CT image (Fig. 17b) show a lytic area involving a dorsal vertebra (white arrows), with increased uptake on PET-CT scan (Fig. 17c). Histological examination revealed the presence of sarcoid disease of dorsal vertebra. Sarcoid lesion is also recognizable in the right ischial tuberosity (white arrows of Fig. 17d and e)

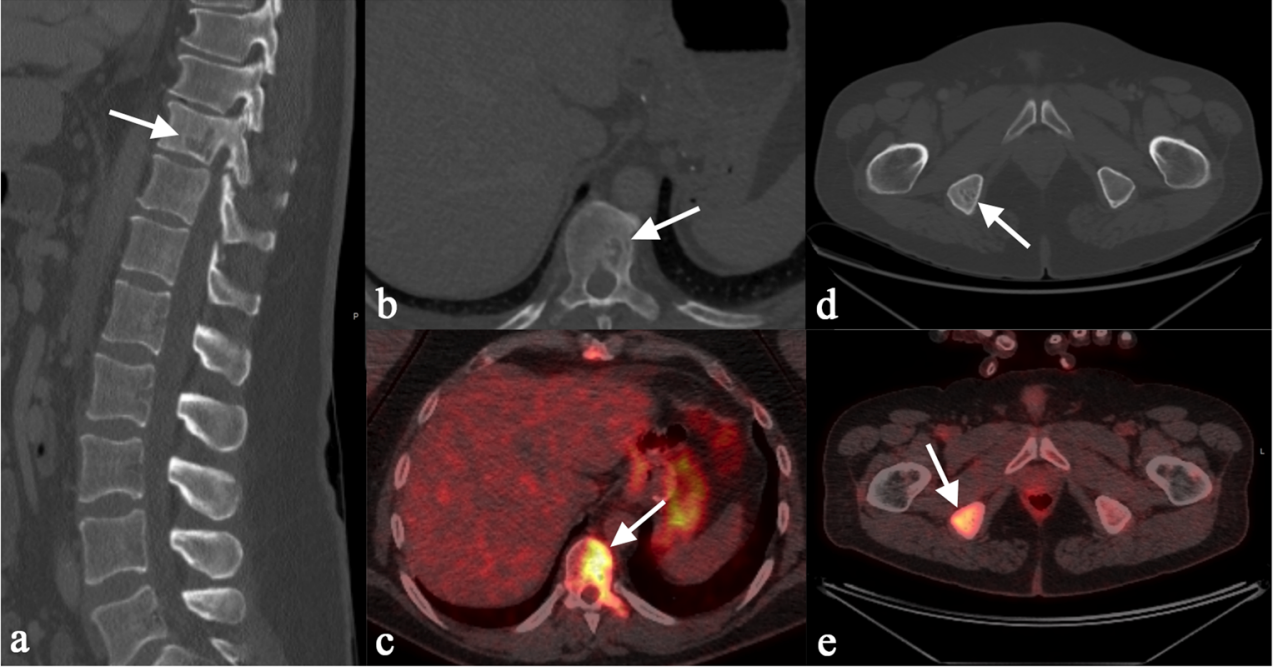

Other manifestations of ocular sarcoidosis include granulomatous iridocyclitis, retinal periphlebitis and chorioretinis; foci of retinal involvement are generally revealed by fluorangiography as "punched-out" lesions (Fig. 20). In 7 to $17 \%$ of cases of ocular sarcoidosis occur conjunctival follicles $[79,80]$.

\section{Cutaneous sarcoidosis}

In sarcoidosis, cutaneous involvement occurs in 20-35\% of patients [81]. The cutaneous lesions are distinguished as "non-specific inflammatory type" and "specific type" [82].

Erythema nodosum is the most common nonspecific cutaneous lesion of sarcoidosis. In most cases it occurs with subcutaneous erythematous nodules (Fig. 21a), often observed on anterior tibia, accompanied by systemic symptoms, such as fever, malaise or polyarthralgias [83].

The term "specific" is misleading, because clinically lesions are not specific to sarcoidosis, and the only way to make a diagnosis is biopsy. Papule (Fig. 21b) is the most common specific cutaneous lesion of sarcoidosis: although the face is the main location, it may occur anywhere and may be of various colours. Larger and flat-
Fig. 1849 year-old woman with axial skeleton involvement. Axial CT images show osteosclerotic lesions (arrowheads) of dorsal vertebrae (Fig. 18a), sacrum (Fig. 18b), and bilateral iliac crest (Fig. 18b). A lymphadenopathy can be also observed on Fig. $18 \mathrm{~b}$ (white asterisk). Coronal reconstruction clearly depicts small osteosclerotic foci in dorsal vertebrae. Sagittal reconstruction (Fig. 18d) demonstrates lesions in contiguous or non-contiguous vertebrae in the dorsal and lumbar spine

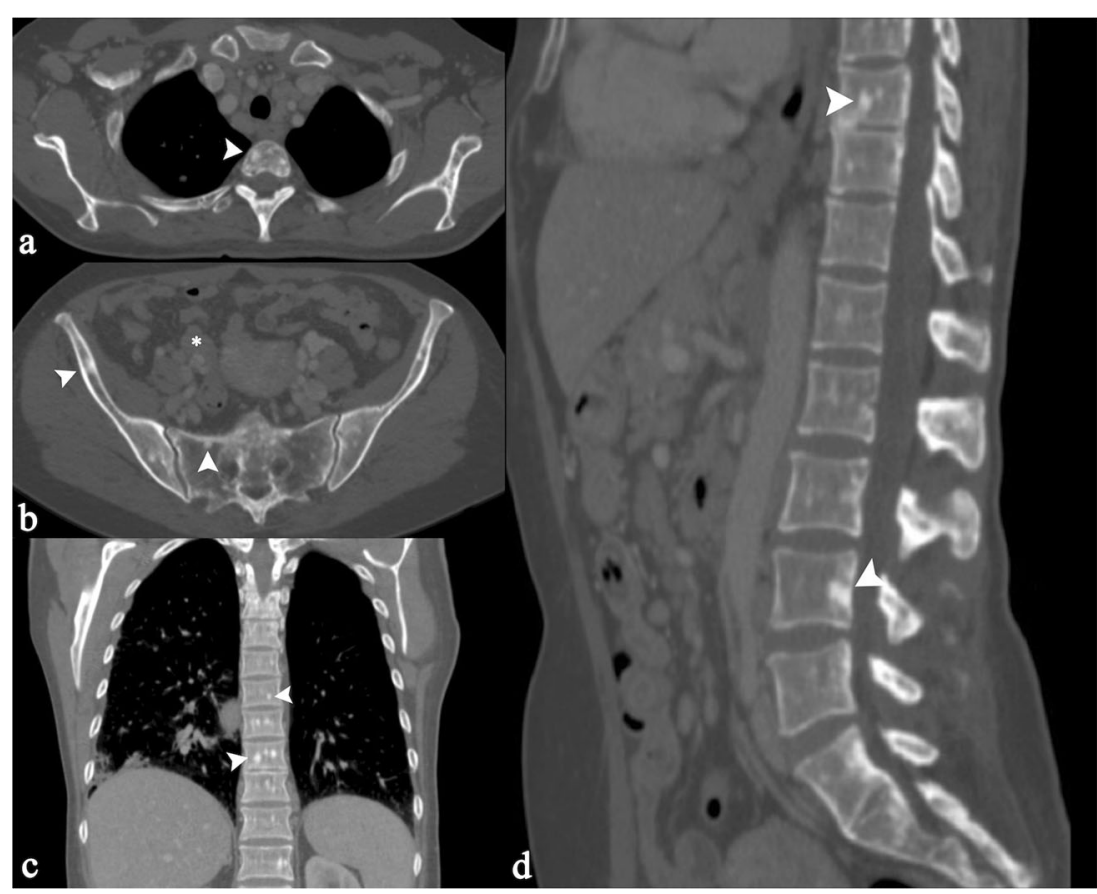




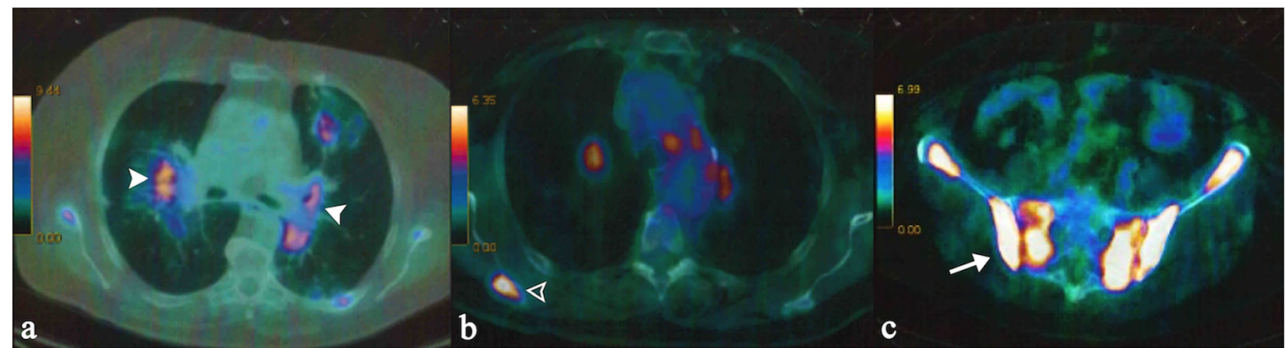

Fig. 19 Skeletal sarcoidosis in a 71-year-old woman. Bilateral thoracic hilar lymphadenopathy is shown on PET-CT (Fig. 19a, white arrowheads). Increased sites of metabolic activity are also recognizable in the right scapula (Fig. 19b), in the sacrum and in the iliac crest (Fig. 19d). In presence of thoracic features of sarcoidosis, bone sites of increased uptake can be interpreted as "skeletal sarcoidosis" topped plaques (Fig. 21c) are very frequent and can be single or multiple; the lesions are located on the face, trunk or extremities.

A characteristic clinical manifestation of cutaneous sarcoidosis is lupus pernio (Fig. 21d): it appears as chronic and indurated papules or plaques in the middle-face, particularly the alar rim of the nose.

The diagnosis of cutaneous sarcoidosis is performed with histological examination of a cutaneous biopsy, which shows the presence of sarcoidal granuloma without any cornoid lamella.

\section{Cardiac sarcoidosis}

Cardiac involvement with clinical manifestations occurs in 2$7 \%$ of patients, but the occult form is much more present [84-86].

Sarcoidosis characteristic granulomatous lesion manifests in any part of the heart, but the myocardium is most frequently involved [87]. In order of frequency, the areas most affected are the left ventricular wall, interventricular septum, papillary muscles, right ventricula and atria [88, 89]. Valvular involvement is rare, but the impaired
Fig. 20 A 62-year-old woman with retinal involvement. Patient complained a left superior palpebral neoformation, which was subsequently biopsied: histological examination revealed the presence of a sarcoid nodule. She also referred to light flashes and blurred vision. Digital retinal angiography scan shows "punched-out" choroidoretinal lesions (white arrows on Fig. 20a-d). Chest CT (Fig. 20e and $\mathrm{f}$ ) demonstrates mediastinal nodal enlargement, suggesting sarcoidosis in stage I

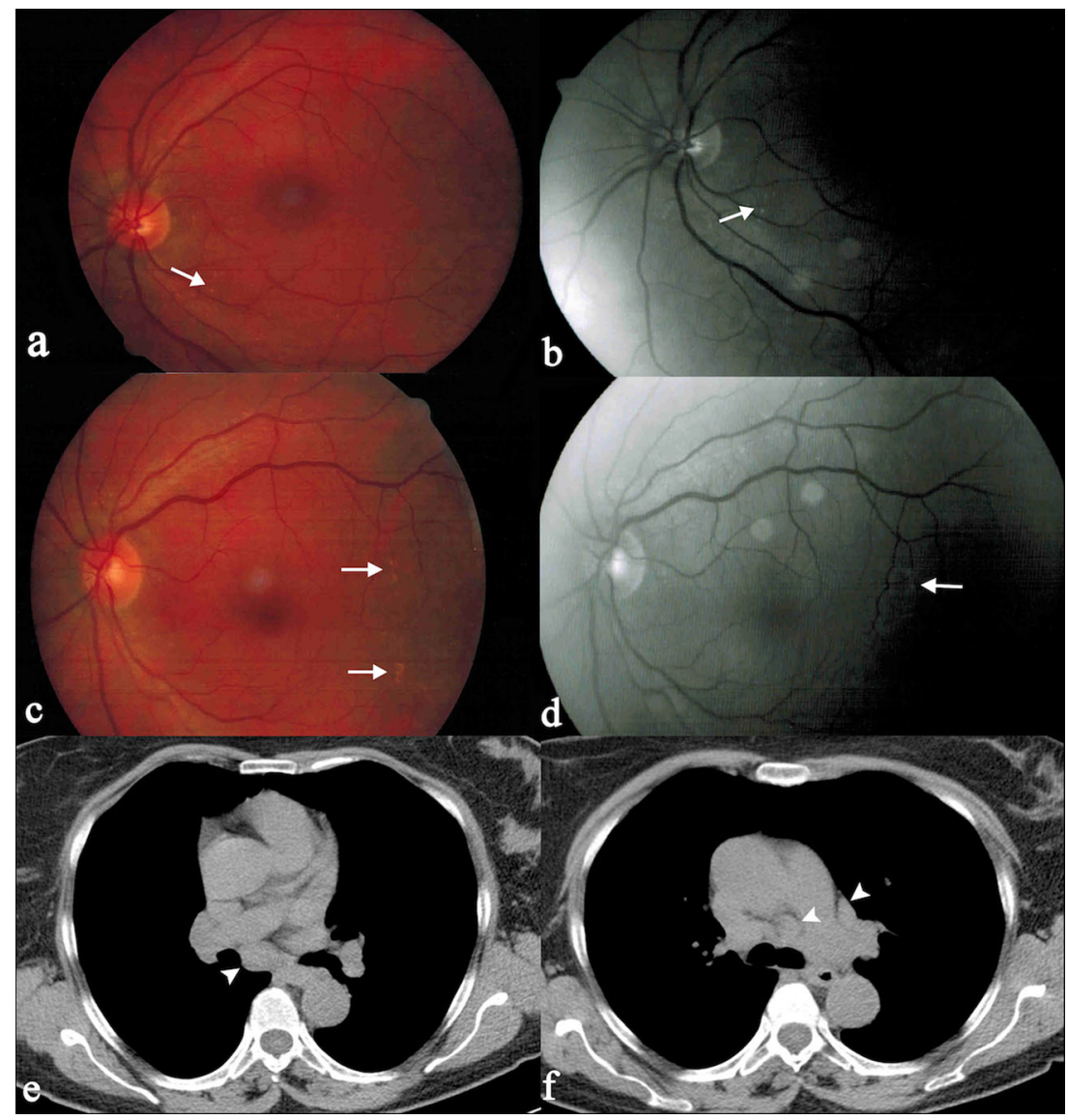


Fig. 21 Pattern of skin involvement in different patients with sarcoidosis. Erythema nodosum occurs with subcutaneous erythematous nodules, as well recognizable on Fig. 21a; it represents the most common non-specific lesions of cutaneous disease. Papules, clearly appreciable on Fig. 21b, represent the most common "specific" cutaneous manifestation of sarcoidosis: they may occur anywhere. Multiple large annular plaques can be a cutaneous appearance of sarcoidosis (Fig. 21c). Finally, Fig. 21d shows a lupus pernio, which represents a typical clinical manifestation of cutaneous sarcoidosis

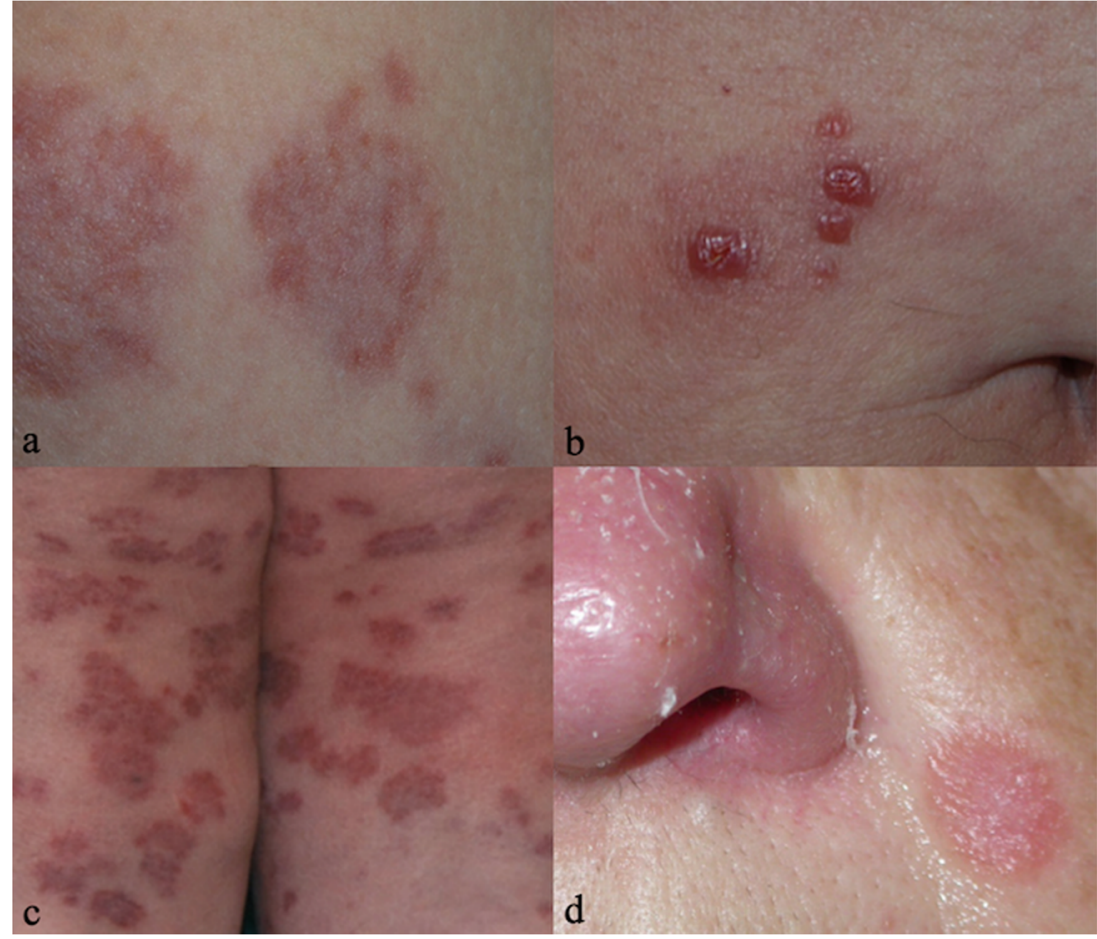

functioning of the cardiac valves may occur after sarcoid reaction of the papillary muscles $[88,90]$. Pericardium involvement may be present, rarely determining constrictive pericarditis [91].

Gadolinium-enhanced cardiac MRI allows us to detect differences between normal tissue and altered tissue, the latter displaying areas of focal enhancement, particularly in the myocardial wall or subepicardial region (Fig. 22) [92, 93]. In addition, other MRI findings include mural oedema, pericardial effusion, myocardial or pericardial thickening and segmental wall motion abnormalities.
Radionuclide scans with gallium, citrate, and thallium are used for diagnosis and follow-up in patients with cardiac sarcoidosis [94, 95]. PET-CT is a technique for diagnosis of active involvement of cardiac sarcoidosis and can be used for the thoracic and extra-thoracic stage of the disease [96].

\section{Conclusions}

Abdominal, neural, musculo-skeletal, cutaneous, ocular and cardiac sarcoidosis has extremely variable clinical features; their imaging findings can often simulate other diseases,

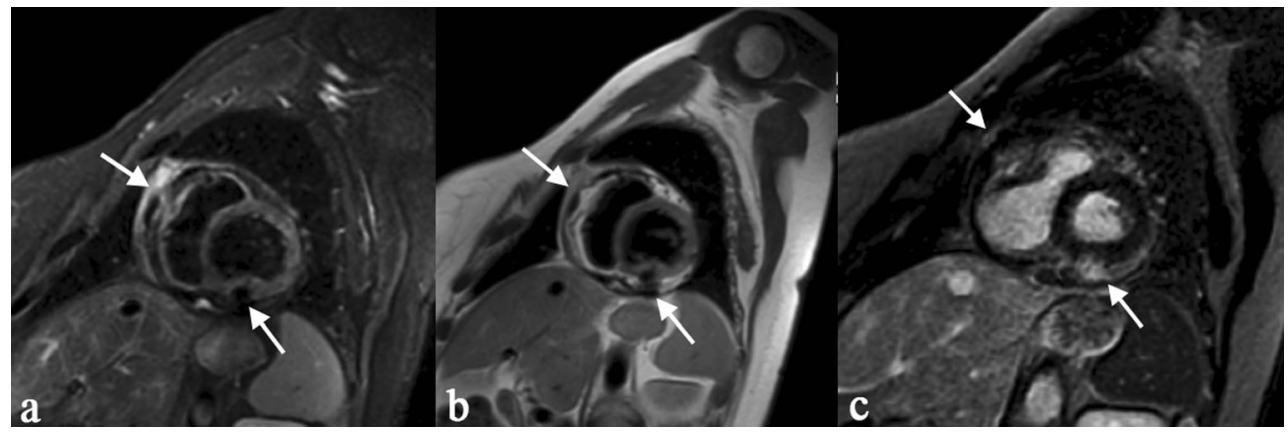

Fig. 22 Cardiac MRI involvement in a patient with systemic sarcoidosis. Triple inversion recovery (Fig. 22a) and doubleinversion recovery sequences (Fig. 22b), both obtained on short axis views, clearly show hypointense calcified myocardial and pericardial nodules (white arrows). After gadolinium administration, foci of delayed enhancement (white arrows), involving also the pericardium, are recognizable (Fig. 22c) 
namely malignancies. Sarcoidosis should be considered in the differential diagnosis of multiple lesions of brain, abdomen and bones in patients with suspected or proved disease.

In patients with pulmonary sarcoidosis, a careful evaluation of patients' symptoms is mandatory in order to identify other locations of the disease. Radiologists, correlating imaging and clinical-pathologic findings, play an important role in diagnosis and follow-up of the disease, in order to reduce its morbidity and mortality.

Open Access This article is distributed under the terms of the Creative Commons Attribution 4.0 International License (http:// creativecommons.org/licenses/by/4.0/), which permits unrestricted use, distribution, and reproduction in any medium, provided you give appropriate credit to the original author(s) and the source, provide a link to the Creative Commons license, and indicate if changes were made.

\section{References}

1. Joint Statement of the American Thoracic Society (ATS), the European Respiratory Society (ERS) and the World Association of Sarcoidosis and Other Granulomatous Disorders (WASOG) adopted by the ATS Board of Directors and by the ERS Executive Committee (1999) Statement on sarcoidosis. Am J Respir Crit Care Med 160:736-755

2. Gezer NS, Başara I, Altay C, Harman M, Rocher L, Karabulut N et al (2015) Abdominal sarcoidosis: cross-sectional imaging findings. Diagn Interv Radiol 21:111-117

3. Judson MA (2007) Extrapulmonary sarcoidosis. Semin Respir Crit Care Med 28:83-101

4. ACCESS Research Group (1999) Design of a Case Control Etiology Study of Sarcoidosis (ACCESS). J Clin Epidemiol 52: 1173-1186

5. Baughman RP, Teirstein AS, Judson MA, Rossman MD, Yeager $H$ Jr, Bresnitz EA et al (2001) Case Control Etiologic Study of Sarcoidosis (ACCESS) research group. Clinical characteristics of patients in a case control study of sarcoidosis. Am J Respir Crit Care Med 164:1885-1889

6. Talmi D, Smith S, Mulligan ME (2008) Central skeletal sarcoidosis mimicking metastatic disease. Skeletal Radiol 37:757-761

7. Powell JL, Cunill ES, Gajewski WH, Novotny DB (2005) Sarcoidosis mimicking recurrent endometrial cancer. Gynecol Oncol 99:770-773

8. Iannuzzi MC, Rybicki BA, Teirstein AS (2007) Sarcoidosis. N Engl J Med 357:2153-2165

9. Morimoto T, Azuma A, Abe S, Usuki J, Kudoh S, Sugisaki K et al (2008) Epidemiology of sarcoidosis in Japan. Eur Respir J 31:372-379

10. Cottin V (2013) Interstitial lung disease. Eur Respir Rev 22:26-32

11. Rao DA, Dellaripa PF (2013) Extrapulmonary manifestations of sarcoidosis. Rheum Dis Clin North Am 39:277-297

12. Rybicki BA, Major M, Popovich J Jr, Maliarik MJ, Iannuzzi MC (1997) Racial differences in sarcoidosis incidence: a 5-year study in a health maintenance organization. Am J Epidemiol 145:234-241

13. Iannuzzi MC, Rybicki BA (2007) Genetics of sarcoidosis: candidate genes and genome scans. Proc Am Thorac Soc 4:108-116

14. Roberts SD, Mirowski GW, Wilkes D, Kwo PY, Knox KS (2004) Sarcoidosis. Part II: extrapulmonary and systemic manifestations. J Am Acad Dermatol 51:628-630
15. Jamilloux Y, Kodjikian L, Broussolle C, Sève P (2014) Sarcoidosis and uveitis. Autoimmun Rev 13:840-849

16. Koyama T, Ueda H, Togashi K, Umeoka S, Kataoka M, Nagai S (2004) Radiologic manifestations of sarcoidosis in various organs. Radiographics 24:87-104

17. Haimovic A, Sanchez M, Judson MA, Prystowsky S (2012) Sarcoidosis: a comprehensive review and update for the dermatologist: part I. Cutaneous disease. J Am Acad Dermatol 66(699):e1-e18

18. Siltzbach LE, James DG, Neville E, Turiaf J, Battesti JP, Sharma OP et al (1974) Course and prognosis of sarcoidosis around the world. Am J Med 57:847-852

19. Vardhanabhuti V, Venkatanarasimha N, Bhatnagar G, Maviki M, Iyengar S, Adams WM et al (2012) Extra-pulmonary manifestations of sarcoidosis. Clin Radiol 67:263-276

20. Karagiannidis A, Karavalaki M, Koulaouzidis A (2006) Hepatic sarcoidosis. Ann Hepatol 5:251-256

21. Warshauer DM, Lee JKT (2004) Imaging manifestations of abdominal sarcoidosis. AJR Am J Roentgenol 182:15-28

22. Ayyala US, Padilla ML (2006) Diagnosis and treatment of hepatic sarcoidosis. Curr Treat Options Gastroenterol 9:475-483

23. Hercules HD, Bethlem NM (1984) Value of liver biopsy in sarcoidosis. Arch Pathol Lab Med 108:831-834

24. Jung G, Brill N, Poll LW, Koch JA, Wettstein M (2004) MRI of hepatic sarcoidosis: large confluent lesions mimicking malignancy. AJR Am J Roentgenol 183:171-173

25. Hegde AN, Kohli A (2005) Multiple hepatosplenic nodules. Br J Radiol 78:1116-1117

26. Sekine T, Amano Y, Hidaka F, Takagi R, Machida T, Naito Z et al (2012) Hepatosplenic and muscular sarcoidosis: characterization with MR imaging. Magn Reson Med Sci 11:83-89

27. Warshauer DM (2007) Splenic sarcoidosis. Semin Ultrasound CT MR 28:21-27

28. Kataoka M, Nakata Y, Hiramatsu J, Okazaki K, Fujimori Y, Ueno Y et al (1998) Hepatic and splenic sarcoidosis evaluated by multiple imaging modalities. Intern Med 37:449-453

29. Taavitsainen M, Koivuniemi A, Helminen J, Bondestam S, Kivisaari L, Pamilo M et al (1987) Aspiration biopsy of the spleen in patients with sarcoidosis. Acta Radiol 28:723-725

30. Selroos O, Koivunen E (1983) Usefulness of fine-needle aspiration biopsy of spleen in diagnosis of sarcoidosis. Chest 83:193-195

31. Iwai K, Takemura T, Kitaichi M, Kawabata Y, Matsui Y (1993) Pathological studies on sarcoidosis autopsy. II. Early change, mode of progression and death pattern. Acta Pathol 43:377-385

32. Warshauer DM, Molina PL, Hamman SM, Koehler RE, Paulson EK, Bechtold RE et al (1995) Nodular sarcoidosis of the liver and spleen: analysis of 32 cases. Radiology 195:757-762

33. Penna C, Deroide GA (2003) Images in clinical medicine. Splenic sarcoidosis. N Engl J Med 349:16

34. Elsayes KM, Narra VR, Mukundan G, Lewis JS Jr, Menias CO, Heiken JP (2005) MR imaging of the spleen: spectrum of abnormalities. Radiographics 25:967-982

35. Warshauer DM, Semelka RC, Ascher SM (1994) Nodular sarcoidosis of the liver and spleen: appearance on MR images. J Magn Reson Imaging 4:553-557

36. Prabhakar HB, Rabinowitz CB, Gibbons FK, O'Donnell WJ, Shepard JA, Aquino SL (2008) Imaging features of sarcoidosis on MDCT, FDG PET, and PET/CT. AJR Am J Roentgenol 190(3 Suppl):S1-6

37. Folz SJ, Johnson CD, Swensen SJ (1995) Abdominal manifestations of sarcoidosis in CT studies. J Comput Assist Tomogr 19:573-579

38. Bernaciak J, Spina JC, Curros ML, Maya G, Venditti J, Chacon C (2002) Case report: peritoneal sarcoidosis in an unusual location. Semin Respir Crit Care Med 23:597-600 
39. Uthman IW, Bizri AR, Khalifeh MJ (2002) Peritoneal sarcoidosis. Semin Arthritis Rheum 31:353

40. Warshauer DM, Dumbleton SA, Molina PL, Yankaskas BC, Parker LA, Woosley JT (1994) Abdominal CT findings in sarcoidosis: radiologic and clinical correlation. Radiology 192:93-98

41. Baughman RP, Lower EE. Sarcoidosis (2008) In: Fauci A, Braunwald E, Kasper DL, Hauser SL, Longo DL, Jameson JL, Loscalzo J (eds.) Harrison's principles of internal medicine. 17th ed. New York: McGraw Hill, 2008

42. Lebacq E, Desmet V, Verhaegen H (1970) Renal involvement in sarcoidosis. Postgrad Med J 46:526-529

43. Rizzato G, Colombo P (1996) Nephrolithiasis as a presenting feature of chronic sarcoidosis: a prospective study. Sarcoidosis Vasc Diffuse Lung Dis 13:167-172

44. Longcope WT, Freiman DG (1952) A study of sarcoidosis; based on a combined investigation of 160 cases including 30 autopsies from The Johns Hopkins Hospital and Massachusetts General Hospital. Medicine (Baltimore) 31:1-132

45. Branson JH, Park JH (1954) Sarcoidosis hepatic involvement: presentation of a case with fatal liver involvement; including autopsy findings and review of the evidence for sarcoid involvement of the liver as found in the literature. Ann Intern Med 40:111-145

46. Agrawal V, Kaul A, Prasad N, Sharma K, Agarwal V (2015) Etiological diagnosis of granulomatous tubulointerstitial nephritis in the tropics. Clin Kidney J 8(5):524-30, Epub 2015 Aug 19

47. Monge M, Miquel O, Dugardin F, Modeliar SS, Glérant JC, Hacène $\mathrm{S}$ et al (2009) Sarcoidosis and the kidney: not only the granulomatous interstitial nephritis. Clin Nephrol 71(2):192-5

48. Goldsmith S, Harris M, Scherer K, Al-Quran S, Vorhis E (2013) Sarcoidosis manifesting as a pseudotumorous renal mass. J Radiol Case Rep 7(5):23-34

49. Berliner AR, Haas M, Choi MJ (2006) Sarcoidosis: the Nephrologist's perspective. Am J Kidney Dis 48:856-870

50. Mahévas M, Lescure FX, Boffa JJ, Delastour V, Belenfant X, Chapelon C et al (2009) Renal sarcoidosis: clinical, laboratory, and histologic presentation and utcome in 47 patients. Medicine (Baltimore) 88:98-106

51. Shah R, Roberson GH, Curé JK (2009) Correlation of MR imaging findings and clinical manifestations in neurosarcoidosis. AJNR Am J Neuroradiol 30:953-961

52. Sharma OP (1997) Neurosarcoidosis: a personal perspective based on the study of 37 patients. Chest 112:220-228

53. Pickuth D, Spielmann RP, Heywang-Kobrunner SH (2000) Role of radiology in the diagnosis of neurosarcoidosis. Eur Radiol 10:941-944

54. Siltzbach LE, James DG, Neville E et al (1974) Course and prognosis of sarcoidosis around the world. Am J Med 57:847-52

55. Zajicek JP, Scolding NJ, Foster O, Rovaris M, Evanson J, Moseley IF et al (1999) Central nervous system sarcoidosis: diagnosis and management. QJM 93:103-117

56. Johns CJ, Michele TM (1999) The clinical management of sarcoidosis: a 50-year experience at the Johns Hopkins Hospital. Medicine (Baltimore) 78:65-111

57. Pawate S, Moses H, Sriram S (2009) Presentations and outcomes of neurosarcoidosis: a study of 54 cases. QJM 102:449-460

58. Roccasalva F, Palmucci S, Piccoli M, Cappello G, Siverino ROA, Puglisi S, Torrisi S, Vindigni V, Vancheri C (2015) Imaging features of extra-thoracic sarcoidosis: a pictorial essay. ECR Poster 2015 Vienna Austria Center doi:10.1594/ecr2015/C-2049

59. Christoforidis GA, Spickler EM, Recio MV, Mehta BM (1999) MR of CNS sarcoidosis: correlation of imaging features to clinical symptoms and response to treatment. AJNR Am J Neuroradiol 20:655-669

60. Hebel R, Dubaniewicz-Wybieralska M, Dubaniewicz A (2015) Overview of neurosarcoidosis: recent advances. J Neurol 262: 258-267
61. Junger SS, Stern BJ, Levine SR, Sipos E, Marti-Masso JF (1993) Intramedullary spinal sarcoidosis: clinical and magnetic resonance imaging characteristics. Neurology 43:333-337

62. Poyanli A, Poyanli O, Sencer S, Akan K, Sayrak H, Acunaş B (2000) Vertebral sarcoidosis: imaging findings. Eur Radiol 10:92-94

63. Rieder H (1910) Über Kombination von kronischer osteomyelitis (spina ventosa) mit lupus pernio. Fortschr Geb Roentgenstr Nuklearmed 15:125

64. Kuzyshyn H, Feinstein D, Kolasinski SL, Eid H (2015) Osseous sarcoidosis: a case series. Rheumatol Int 35(5):925-33

65. Packer CD, Mileti LM (2005) Vertebral sarcoidosis mimicking lytic osseous metastases: development 16 years after apparent resolution of thoracic sarcoidosis. J Clin Rheumatol 11:105-108

66. Balan A, Hoey ET, Sheerin F, Lakkaraju A, Chowdhury FU (2010) Multi-technique imaging of sarcoidosis. Clin Radiol 65:750-760

67. Abril A, Cohen MD (2004) Rheumatologic manifestations of sarcoidosis. Curr Opin Rheumatol 16:51-55

68. Resnik CS (1992) Osseous sarcoidosis, radiologic imaging, and physician interaction. N Y State J Med 92:177-178

69. Nessrine A, Zahra AF, Taoufik H (2014) Musculoskeletal involvement in sarcoidosis. J Bras Pneumol 40:175-182

70. Rothova A (2000) Ocular involvement in sarcoidosis. Br J Ophthalmol 84:110-116

71. Ohara K, Okubo A, Sasaki H, Kamata K (1992) Intraocular manifestations of systemic sarcoidosis. Jpn J Ophthalmol 36:452-457

72. Rothova A, Alberts C, Glasius E, Kijlstra A, Buitenhuis HJ, Breebaart AC (1989) Risk factors for ocular sarcoidosis. Doc Ophthalmol 72:287-296

73. Hunter DG, Foster CS (1994) Ocular manifestations of sarcoidosis In: Albert DM, Jakobiec FA (eds) Principles and practice of ophthalmology. WB Saunders, Philadelphia, pp 443-450

74. Karma A (1979) Ophthalmic changes in sarcoidosis. Acta Ophthalmol Suppl 141:1-94

75. Rothova A, Suttorp-van Schulten MS, Frits Treffers W, Kijlstra A (1996) Causes and frequency of blindness in patients with intraocular inflammatory disease. Br J Ophthalmol 80:332-336

76. Rothova A (1998) Posterior segment involvement in sarcoidosis In: Ohno S, Aoki K, Usui M, Uchio E (eds) Uveitis today. Elsevier, Amsterdam, pp 207-210

77. Stern BJ, Krumholz A, Johns C (1985) Sarcoidosis and its neurological manifestations. Arch Neurol 42:909-16

78. Lower EE, Broderick JP, Brott TG, Baughman RP (1997) Diagnosis and management of neurological sarcoidosis. Arch Intern Med 157:1864-1868

79. Jabs DA, Johns CJ (1986) Ocular involvement in chronic sarcoidosis. Am J Ophthalmol 102:297-301

80. Obenauf CD, Shaw HE, Sydnor CF, Klintworth GK (1978) Sarcoidosis and its ophthalmic manifestations. Am J Ophthalmol 86:648-655

81. Tchernev G, Patterson JW, Nenoff P, Horn LC (2010) Sarcoidosis of the skin: a dermatological puzzle: important differential diagnostic aspects and guidelines for clinical and histopathological recognition. J Eur Acad Dermatol Venereol 24:125-137

82. Marchell RM, Judson MA (2010) Cutaneous sarcoidosis. Semin Respir Crit Care Med 31:442-451

83. Sharma OP (1999) Sarcoidosis of the skin. In: Freedberg IM, Fitzpatrick TB (eds) Fitzpatrick's Dermatology in general medicine, 5th edn. McGraw-Hill, New York, pp 2099-2106

84. Kinney EL, Jackson GL, Reeves WC, Zelis R (1980) Thalliumscan myocardial defects and echocardiographic abnormalities in patients with sarcoidosis without clinical cardiac dysfunction. An analysis of 44 patients. Am J Med 68:497-503

85. Tellier P, Paycha F, Antony I, Nitenberg A, Valeyre D, Foult JM et al (1988) Reversibility by dipyridamole of thallium-201 myocardial scan defects in patients with sarcoidosis. Am J Med 85:189-193 
86. Fahy GJ, Marwick T, McCreery CJ, Quigley PJ, Maurer BJ (1996) Doppler echocardiographic detection of left ventricular diastolic dysfunction in patients with pulmonary sarcoidosis. Chest 109: 62-66

87. Ayyala US, Nair AP, Padilla ML (2008) Cardiac sarcoidosis. Clin Chest Med 29(493-508):ix

88. Roberts WC, McAllister HA Jr, Ferrans VJ (1977) Sarcoidosis of the heart. A clinicopathologic study of 35 necropsy patients (group 1) and review of 78 previously described necropsy patients (group 11). Am J Med 63:86-108

89. Tavora F, Cresswell N, Li L, Ripple M, Solomon C, Burke A (2009) Comparison of necropsy findings in patients with sarcoidosis dying suddenly from cardiac sarcoidosis versus dying suddenly from other causes. Am J Cardiol 104:571-577

90. Shammas RL, Movahed A (1993) Sarcoidosis of the heart. Clin Cardiol 16:462-472

91. Garrett J, O’Neill H, Blake S (1984) Constrictive pericarditis associated with sarcoidosis. Am Heart J 107:394
92. Vignaux O (2005) Cardiac sarcoidosis: spectrum of MRI features. AJR Am J Roentgenol 184:249-254

93. Giesbrandt KJ, Bolan CW, Shapiro BP, Edwards WD, Mergo PJ (2013) Diffuse diseases of the myocardium: MRI-pathologic review of cardiomyopathies with dilatation. AJR Am J Roentgenol 200:W274-282

94. Tawarahara K, Kurata C, Okayama K, Kobayashi A, Yamazaki N (1992) Thallium-201 and gallium 67 single photon emission computed tomographic imaging in cardiac sarcoidosis. Am Heart J 124: 1383-1384

95. Taki J, Nakajima K, Bunko H, Ohguchi M, Tonami N, Hisada K (1990) Cardiac sarcoidosis demonstrated by Tl-201 and Ga-67 SPECT imaging. Clin Nucl Med 15: 636-639

96. Yang Y, Safka K, Graham JJ, Roifman I, Zia MI, Wright GA et al (2014) Correlation of late gadolinium enhancement MRI and quantitative T2 measurement in cardiac sarcoidosis. J Magn Reson Imaging 39:609-616 